\title{
DOYNE LECTURE THE PATHOLOGY OF THE OUTFLOW SYSTEM IN PRIMARY AND SECONDARY GLAUCOMA
}

\author{
W. R. LEE \\ Glasgow
}

On behalf of my specialty of ophthalmic pathology, I am indebted to the Master of the Oxford Congress for the invitation to present the Doyne Memorial Lecture on the pathology of the outflow system in primary and secondary glaucoma. Although I regard the Doyne Lecture as an awesome responsibility, it has been an enjoyable exercise in preparing for it to go through the contributions of previous Doyne lecturers and to read the remarks made by those who knew Doyne personally. From the various very distinguished Doyne lecturers who have preceded me, I sense that the ethos of this lecture is that speculation is an integral requirement of the speaker. This is not so easy for a pathologist, but I hope that some of the text will be sufficiently controversial to stimulate further research work.

It has also been an enjoyable task to review some of Doyne's published work and to read descriptions of the man and his attitudes to work and to relaxation. The account of the life of Doyne prepared by Catford ${ }^{1}$ was of great value to those who, like myself, were aware of the name only in the context of this lecture. The illustrations in Catford's paper highlight the many facets of the character of Doyne - scholar, musician, clinician, fencer and sailor - elegantly combining the attitudes of the Anglo-Saxon and the Celt to recreation and contemplation. In his generation so many great men appeared to have a multitude of talents, which is something of a rarity in contemporary society. However, the statement which I personally found most endearing and of greatest encouragement when I started to prepare for this lecture, was written in Doyne's textbook in $1896,{ }^{2}$ viz. 'Glaucoma was the most dreaded of all eye diseases'.

On looking through the list of Doyne medallists, I

Correspondence to: Professor W. R. Lee, Department of Ophthalmology, The University of Glasgow, Glasgow G11 6NT, UK. noted that since the contribution of Doyne himself, few pathologists have been honoured. Professor Norman Ashton and the late Professor David Cogan were the only ophthalmic pathologists included in the list. In 1960, Professor Ashton ${ }^{3}$ chose to lecture on the pathology of the outflow channels in glaucoma and I was interested to see that in the final paragraph of his text he wrote 'no doubt this topic will again be chosen by a Doyne Lecturer'. Thus it is appropriate that the problem of glaucoma should again be addressed by a pathologist some 35 years later. In this lecture I have drawn freely on the research material which my colleagues and I have been studying in Glasgow for the past 25 years and I have used this to re-interpret conventional morphology in the light of modern technology which uses molecular biology.

In the 1970s and early 1980s, I had the privilege of collaborating with Ian Grierson and Paul McMenamin in the investigation of the response of the subhuman primate outflow system to a variety of shortterm stresses such as alterations in intraocular pressure and exposure to enzymes. Non-survival experiments such as these provided valuable information on the functional morphology of the normal tissue.

The study of diseased tissue was not so easily undertaken due to a paucity of suitable specimens appropriately fixed and prepared for sophisticated pathological investigations. Accordingly for the last 25 years I have adopted the policy of preparing any potentially interesting specimen for electron microscopy in the hope that eventually it would be possible to generate a cohesive description of those disẹase processes which test the outflow system to destruction. The intention was to integrate the results of pathomorphological investigation with the massive amount of factual information currently available in 


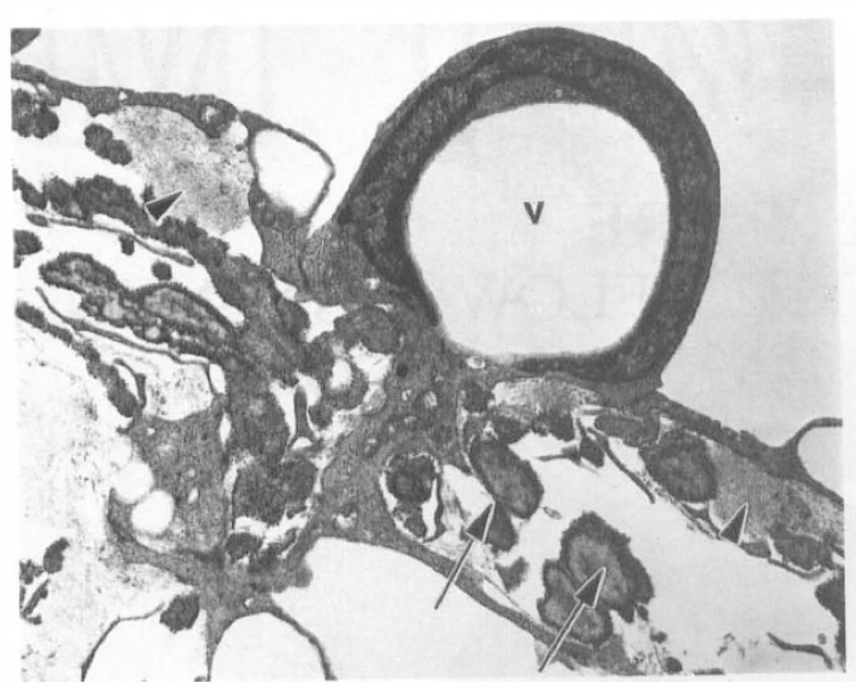

Fig. 1. A giant vacuole (v) in the lining endothelium of Schlemm's canal in a 60-year-old male suffering from partial angle closure with overperfusion in this part of the meshwork. The underlying cribriform layer contains a fine fibrillar extracellular matrix (arrowheads) and electrondense clumps (arrows). (Transmission electron micrograph, $\times 5000)$

the many excellent textbooks dealing with the clinical aspects of glaucoma in all its forms. ${ }^{4-6}$

In this lecture it is appropriate to first review the current status of knowledge concerning the functional anatomy of the outflow system. Thereafter various pathological processes will be described in order to provide an understanding of the mechanisms which can lead to breakdown of the tissue and an increased resistance to aqueous outflow and, ultimately, to intractable glaucoma.

It is currently accepted that the outflow system has the following functional properties and can behave as:

1. a one-way valve ${ }^{7}$

2. a resistor which maintains intraocular pressure, ${ }^{7}$

3. a selective filter ${ }^{8}$ which (a) removes particulate materials (endogenous and exogenous), (b) permits the escape of cellular infiltrates and (c) acts as an immunological recognition system $;^{9}$

4. a pressure sensor. ${ }^{10}$

\section{THE NORMAL OUTFLOW SYSTEM}

The Outflow System as a One-Way Valve Morphological investigation of the mechanisms for aqueous transport across the lining endothelium of Schlemm's canal was initiated by Garron et al. ${ }^{11}$ in 1958 and Holmberg ${ }^{12}$ in 1959 with the discovery that the monolayer contained large membrane-bound spaces which were subsequently described as giant vacuoles. The nature of giant vacuoles was not fully appreciated until Tripathi ${ }^{13}$ provided the hypothesis that a giant vacuole is preceded by the formation of an invagination and that emptying of the vacuole

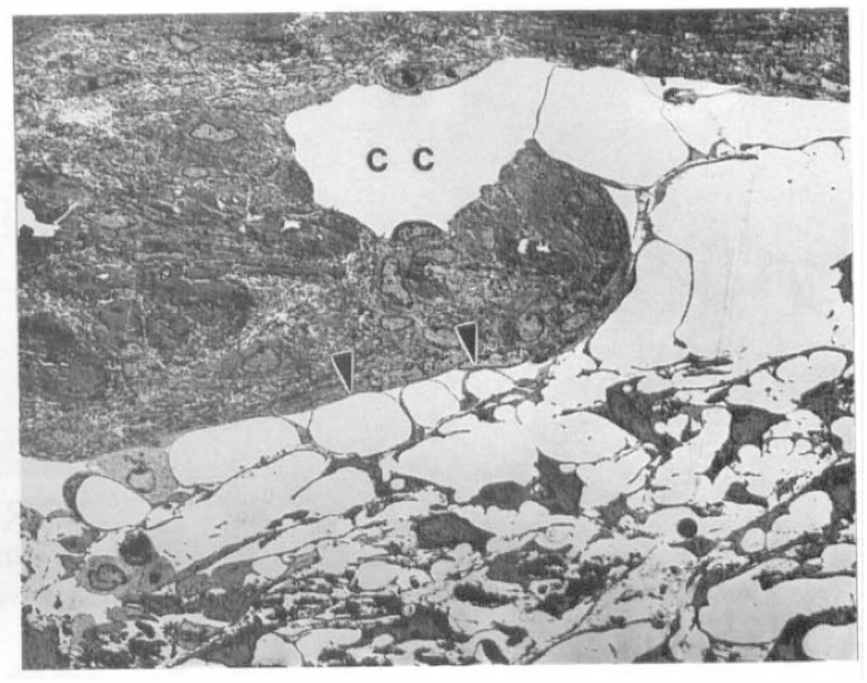

Fig. 2. There is marked distension of the cribriform layer of the rhesus monkey subject to an intracameral perfusion at $50 \mathrm{mmHg}$ for 1 hour prior to fixation. The collector channel (cc) is blocked and the giant vacuoles (arrowheads) are adherent to the outer wall endothelium. (Transmission electron micrograph, $\times 900$ )

occurs after a hole or pore forms in the cytoplasm which bulges into Schlemm's canal. The structure (Fig. 1) then acts as a transcellular channel which permits rapid fluid transport when the pressure in the cribriform layer is high; conversely with collapse of the cribriform layer at low intraocular pressure, blood reflux is prevented - hence the concept of the 'one-way valve' (for review see Tripathi and Tripathi ${ }^{14}$ ).

In the following decades the importance of the giant vacuole system in bulk flow through an endothelial monolayer became accepted, not only for transport of aqueous from the eye, but also for passage of cerebrospinal fluid into the intracranial venous sinuses. ${ }^{14}$ The pressure-sensitive nature of the giant vacuole bulk transfer system was demonstrated in 1973 by Johnstone and Grant ${ }^{15}$ working in Boston on human autopsy eyes and on monkey eyes, and their studies emphasised the importance of intraocular pressure on the numbers of giant vacuoles in the lining endothelium of Schlemm's canal.

The hypothesis of transcellular bulk flow did not go unchallenged and the possibility that the vacuolar structures were autolytic artefacts persisted. ${ }^{3}$ However, subsequent conclusive studies proved the opposite. ${ }^{16}$ In the early 1970 s the working hypothesis of Grierson and myself was that, if the giant vacuoles were not artefactual, there would be an increase in number and size in response to pressure and the concomitant flow of aqueous through the trabecular tissues. Painstaking morphometric studies carried out on the monkey eye by Grierson ${ }^{17-19}$ provided data to prove that the number and size of giant vacuoles increased with a pressure rise (as 


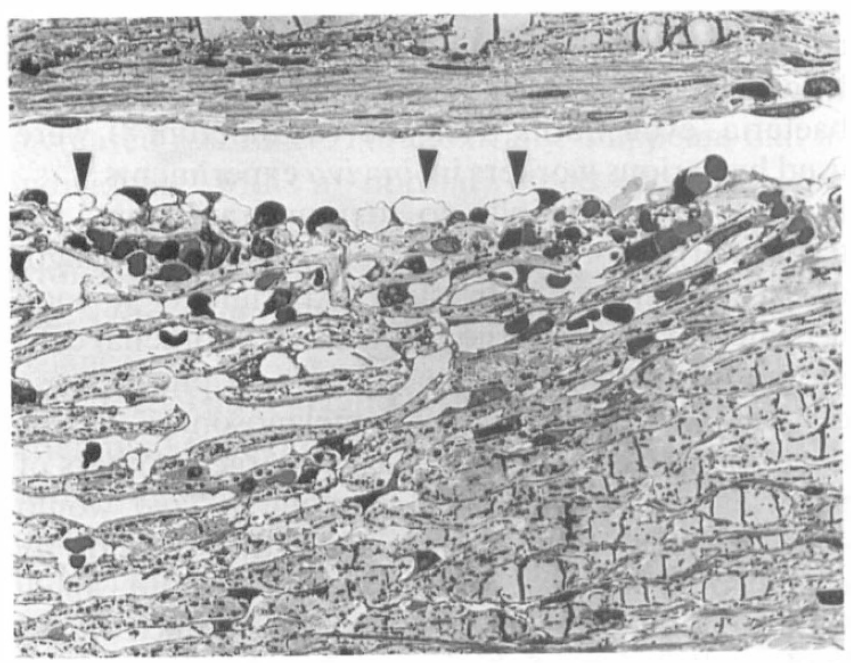

Fig. 3. A light micrograph to show numerous giant vacuoles (arrowheads) in the human lining endothelium of Schlemm's canal after fixation perfusion at $30 \mathrm{mmHg}$. $(\times 475)$

maintained by a manometer in vivo) in the normal physiological range. Thus a 'giant vacuole count' became a mathematical indicator of both pressure and flow through the outflow system, particularly if this was associated with distension of the cribriform layer.

Similarly the number of flow channels and pores (as determined by scanning and transmission electron microscopy) in the lining endothelium also increased in response to an increase in intraocular pressure. ${ }^{20-23}$ The morphological observations with regard to the response of the outflow system to intraocular pressure were confirmed and accepted by other workers in the field and recent review articles describe the praiseworthy contributions of Alvarado et al. ${ }^{24}$ Bill $^{25}$ and Rohen et al. ${ }^{26}$

The combination of studies on the sub-human primate eye and the human eye revealed that the young monkey or baboon eye had a much more pliable outflow system than the human eye. In the subhuman primate, the pressure/flow vacuole relationship held at relatively low pressures for fairly short experimental time intervals (1-2 hours), but at pressure levels of the order of $50 \mathrm{mmHg}$, large bulges in the delicate cribriform layer blocked off the collector channels, ${ }^{15,22}$ with presumably an increase in resistance to outflow (Fig. 2). In addition, large giant vacuoles in the lining endothelium of the inner trabecular wall became adherent to the outer wall endothelium and it was not difficult to find signs of rupture and disorganisation in the monolayer. We speculated that disruption of the extracellular matrix in the distended cribriform layer would, by allowing free passage of aqueous, act to counterbalance the increased resistance due to plugging of collector channels. This form of disorganisation would provide detectable, but erroneous, information in overzeal- ous physiological studies of aqueous outflow dynamics.

The importance of glycoproteins in resistance to aqueous outflow was investigated by McMenamin, who conducted a series of experiments in which the baboon anterior chamber was perfused in vivo with a solution containing hyaluronidase at physiological pressures $(18 \mathrm{mmHg}){ }^{27,28}$ The prolonged perfusion experiments with and without the addition of hyaluronidase for periods of 4-6 hours on the primate eye, i.e. with a combination of physiological measurements and morphometry, ${ }^{27}$ failed to demonstrate any effect of the enzyme. This was because the perfusion technique caused such distension in the control tissue that an enzyme effect, if it indeed exists, was totally obscured. Our observations were confirmed by another recent study $^{29}$ which also demonstrated that the distension of the cribriform layer obstructed the collector channels. Our conclusion was that the pliability of the monkey outflow system rendered our physiological data unreliable.

Coincidental with the experimental work, it was our policy to study drug effects on the human outflow system using eyes obtained immediately after surgical enucleation, in most cases in treatment for posterior uveal melanoma. In the early experiments the globes were fixed immediately by immersion in glutaraldehyde. We found that pre-enucleation treatment of the patients with topical pilocarpine ${ }^{30}$ resulted in a rotation of the scleral spur and a statistically significant increase in the number of giant vacuoles in the lining endothelium of Schlemm's canal. We concluded that rotation of the spur opened the inter-trabecular spaces and allowed aqueous to pass more easily into the cribriform layer and through the endothelium of Schlemm's canal.

This hypothesis was strengthened by experiments on the baboon eye $\mathrm{e}^{31,32}$ which revealed an absence of a detectable effect on the giant vacuole count after instillation of topical pilocarpine. This was attributed to the fact that this species does not possess a scleral spur so that constriction of the muscle does not widen the meshwork. In another series of experiments, pretreatment with topical timolol of the human eye prior to enucleation for melanoma had no effect on the giant vacuole count by comparison with untreated controls. ${ }^{33}$ It is generally accepted that the pressure-lowering effect of timolol is due to inhibition of aqueous inflow and it was not unexpected that there were no detectable changes in the outflow system.

These experiments were followed by an investigation into the rapidity with which the human meshwork can respond to changes in pressure. ${ }^{34}$ Eighteen enucleated human eyes were perfused with glutaraldehyde solution at a pressure of $30 \mathrm{mmHg}$ on the assumption that the adaptation to this pressure level 
would be captured by diffusion of glutaraldehyde, which rapidly causes the tissue to become firm and causes increasing resistance to outflow. ${ }^{16}$ An additional factor to be considered in hindsight is that the stabilisation of the tissue was probably protective in terms of excessive pressure stress.

It was reassuring to find that the elderly human outflow system was much more robust in the face of this insult than was that of the sub-human primate. In this study of the trabecular meshwork in eyes perfused immediately after enucleation ${ }^{34}$ the incidence of giant vacuoles was 3-5 times greater in the perfused eyes than in the control, immersion-fixed eyes (Fig. 3). In the perfused eyes (age 20-60 years) the mean giant vacuole count was between 15 and 30 per section, while in the elderly ( $70-80$ years) the count was between 10 and 20. In the immersion-fixed specimens the giant vacuole count declined from a maximum of 10 in the younger age groups to less than 5 per section in the later decades. It should be stressed that this form of perfusion fixation applied a $30 \mathrm{mmHg}$ pressure differential directly across the meshwork and the canal endothelium, because the pressure in the episcleral veins was of course zero in the enucleated eye. One of the important findings was a decrease in the number of giant vacuoles with age in both the perfused and immersion-fixed eyes. However, it was also possible to demonstrate an agerelated decrease in the size of canal due to hyalinisation of the scleral sulcus and enlargement of the scleral spur. When the age-related reduction in the circumference of the canal was taken into account, the capacity of the endothelium to form giant vacuoles no longer exhibited an age-related decline. In none of the human tissue used for this study was there any evidence of tissue prolapse into collector channels, nor was there narrowing of the canal with contact between the inner and outer walls as had been observed in the rhesus monkey and baboon eyes.

The final conclusions from the numerous studies described above were that the number and dimensions of the giant vacuoles in the lining endothelium were an indicator of the status of the outflow system in its function as a one-way valve. The work on human tissue also introduced the caveat that there was an apparent decline in function as the ageing process continues and this had to be taken into account in the study of more advanced disease in the outflow system.

\section{The Outflow System as a Filter}

The principal awareness of the outflow system as a filter came as a result of experiments intended to determine the size of the pores in the giant vacuoles present in the lining endothelium of Schlemm's canal. A variety of particles (carbon, melanosomes, colloidal gold, ferritin, latex microspheres, fibrin, leucocyte debris, intact red cells and red cell debris, bacteria, even fibrils from the cat tapetum ${ }^{35}$ ) were used by various workers in in vivo experiments. ${ }^{8,36,37}$ It was also possible to demonstrate that the trabecular endothelial cells were capable of phagocytosis in vitro. ${ }^{38-40}$ In such experiments it soon became obvious that the trabecular endothelial cells in culture had a selective capacity to phagocytose certain particles, particularly melanosomes. It was tempting to assume that release of large numbers of particles into the anterior chamber in vivo would overload the system and that this would be deleterious because cell separation would allow water influx into the trabecular beams which would lead to occlusion of the intertrabecular spaces. The nature of the particles is of importance in the stimulus to phagocytosis and its effects. For example, the system can readily remove melanin granules, as evidenced by the complicated survival experiments which have shown that the monkey outflow system can recover from repeated injections of melanin into the trabecular meshwork. ${ }^{41}$

\section{The Outflow System as a Resistor}

The main impetus to the intensive study of the trabecular meshwork was the desire to identify a morphological cause for the increased resistance which occurs in primary open angle glaucoma, a topic which is discussed later. Since there is overwhelming evidence that in normal tissue the main locus of resistance is the outermost layer of the trabecular meshwork (the cribriform layer or juxtacanalicular layer), ${ }^{7,37.42-45}$ morphologists in the last two decades have, using light microscopy, immunocytochemistry and electron microscopy, energetically attempted to identify those components of the extracellular matrix which might be responsible for resistance to fluid flow. At the ultrastructural level using conventional processing techniques, it was relatively easy to classify different constituents on purely morphological grounds, ${ }^{26,37,45}$ viz. 'amorphous', 'fine fibrillar', 'wide banded', 'basement-membrane-like', etc., even though the biochemical nature was unknown. Rohen and his co-workers ${ }^{26,37,46,47}$ concluded that electron-dense plaques of collagenous and elastic-like material, so prominent in the cribriform layer (Fig. 1), were the most likely materials to cause resistance to aqueous outflow.

One interesting feature of the outflow system is that with ageing the trabecular beams become thickened by deposition of a collagenous extracellular matrix on the trabeculae, this being accompanied by deposits on the outer wall of Schlemm's canal. ${ }^{45-47}$ These are all morphological features which suggest that their presence could interfere 
with the capacity to respond to demands for transfer of aqueous fluid and would lead, therefore, to an increased resistance. Paradoxically, it appears that in individuals with a normal blood pressure the intraocular pressure declines with age pari passu with a decline in the rate of aqueous inflow. ${ }^{48}$ so that the system in the normal individual remains in balance.

In recent investigations, Marshall et al. ${ }^{49-51}$ have attempted to identify the various constituents of the extracellular matrix in the cribriform layer using immunocytochemical techniques for the identification of collagens and laminin. The collagen types I, III, IV. V and VI have been located in the trabecular meshwork using immunogold labels at the ultrastructural level. Collagen types I and IV have been

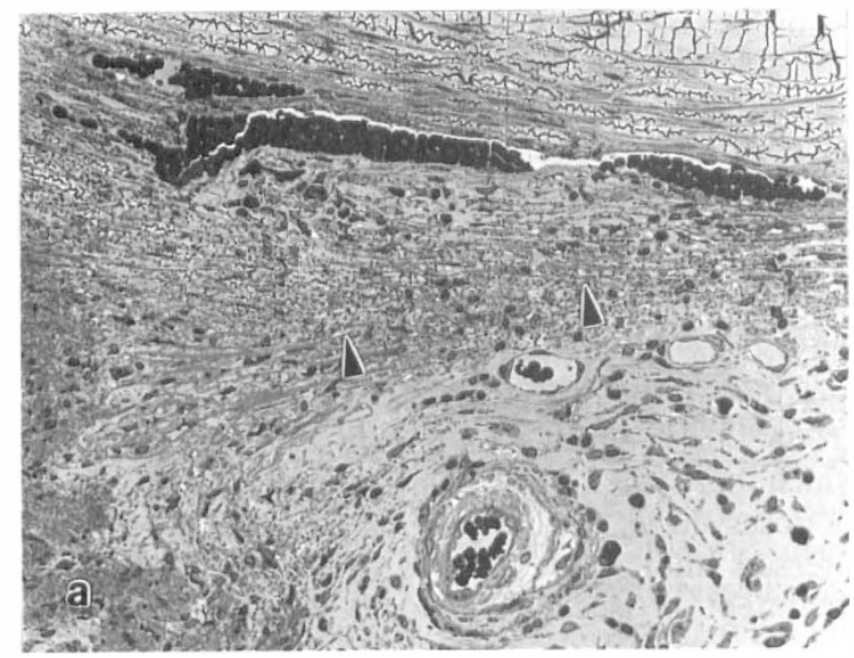

(a)

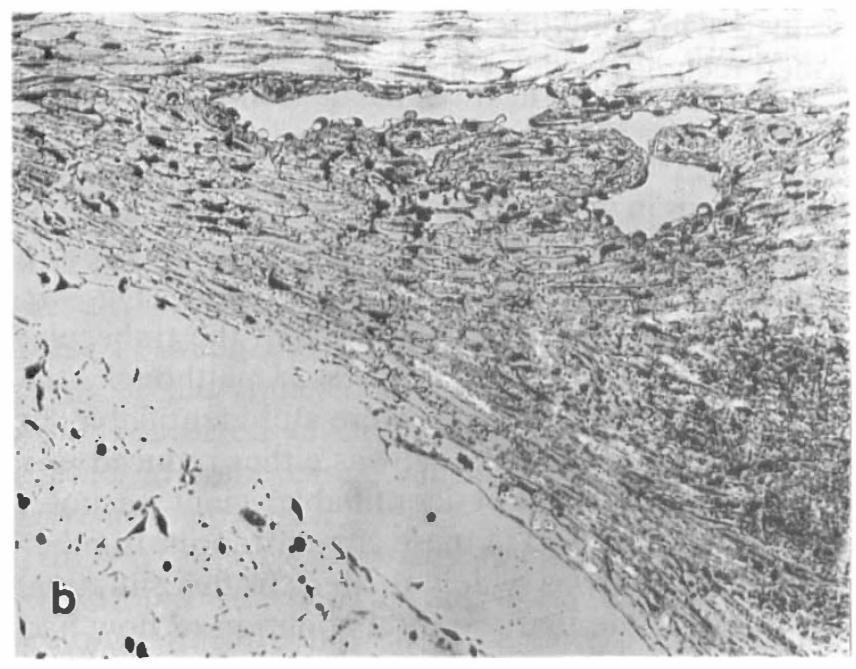

(b) located in the basement membrane of the endothelium lining the canal of Schlemm and in the fine filamentous material beneath the canal endothelial monolayer. Type III collagen was located with type I collagen in the striated collagen fibres in the inner part of the cribriform layer. The significance of these investigations is that type I collagen imparts tensile strength while type III imparts resilience. ${ }^{52}$ Type VI collagen appears as fine fibres which bind the larger fibres of types I and III. This collagen type has been identified by biochemical techniques and the finding was substantiated by the demonstration of mRNA for type VI collagen in the trabecular endothelial cells. ${ }^{53}$ The nature of the electron-dense plaques and wide-banded collagen remains controversial. In one immunohistochemical study, type VI collagen was

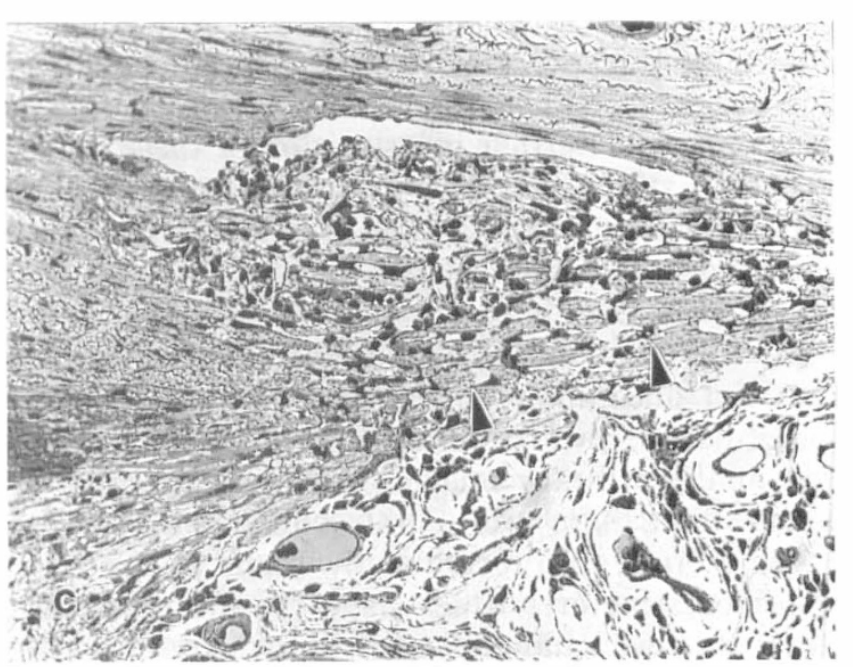

(c)

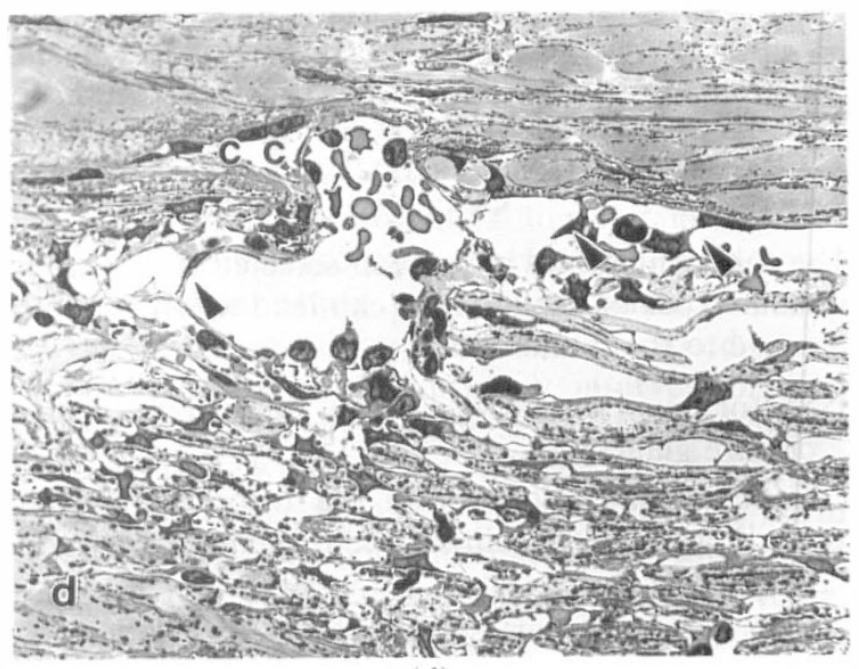

(d)

Fig. 4. (a) In complete angle closure the trabeculae are compressed (arrowheads) and giant vacuoles are absent from the lining endothelium of Schlemm's canal which contains blood. $(\times 200)$ (b) In a sector where the angle is open and the trabeculae appear to be compressed, giant vacuoles are numerous. There is presumably diffusion of aqueous within the meshwork at high pressure. $(\times 200)($ c) Partial angle closure and fusion of the inner trabeculae (arrowheads) is associated with identifiable vacuoles, albeit reduced in number. $(\times 200)(d)$ In one case the cribriform layer was so distended that the collector channel $(c c)$ was occluded by a bulge: the canal is bridged by cellular strands (arrowheads). (Toluidine blue stained plastic sections, $\times 475)$ 
identified in wide-banded collagen, ${ }^{54}$ but other workers have not confirmed this. ${ }^{51}$

Initially, we and others were interested in glycoproteins, which can be demonstrated as a fine filamentous network in the trabecular interspaces by their special affinities for identifiable compounds such as ruthenium red. ${ }^{55}$ Owing to their hydrophilic properties, glycoproteins are considered capable of creating resistance and Ethier et al. ${ }^{43}$ believe that the seemingly electron-empty spaces are in fact filled with gel which contributes significantly to resistance. With better technology, more specific identification can be achieved and the sulphated proteoglycans, both chondroitin sulphate and dermatan sulphate, have been identified in human trabecular tissue, with the latter predominating. ${ }^{56}$ More recently, sialic acids have been demonstrated in the extracellular matrix using immunogold lectins. ${ }^{57}$ Gong et al. ${ }^{58}$ claim that an age-related progressive coalescence of collagen was found in the normal trabecular meshwork and this was associated with a decrease in the amount of proteoglycans. Further investigation of these inconspicuous extracellular matrix constituents may prove important in an understanding of primary open angle glaucoma.

\section{The Outflow System as a Pressure Sensor}

It is not uncommon to find nerves in the human trabecular meshwork, particularly in the scleral spur and in the cribriform layer, and it is tempting to assume that there are neural connections between eye and brain. In a recent study Tamm et al. ${ }^{10}$ have identified structures which have the morphological features of mechanoreceptors within the scleral spur. The possibility that there is some form of neurological control of the intraocular pressure raises possibilities for valuable future research.

\section{THE EFFECTS OF VARIOUS PATHOLOGICAL PROCESSES ON THE HUMAN OUTFLOW SYSTEM}

The following topics have been selected to illustrate various types of insult which can lead to irreversible damage to the human outflow system:

1. Sector overperfusion, as in secondary angle closure glaucoma.

2. Cellular infiltration within the trabecular meshwork, as in 'trabeculitis' due to inflammatory cell infiltration.

3. Deposition of inert substances in the trabecular meshwork, as in the exfoliation syndrome.

\section{EFFECTS OF HIGH PRESSURE ON THE HUMAN OUTFLOW SYSTEM IN ANGLE CLOSURE}

The pathological effects of angle closure on the trabecular meshwork in the primary forms of angle
Table I. Details of specimens used for the study of secondary angle closure on the trabecular meshwork

\begin{tabular}{lll}
\hline Case no. & Patient & Age (years) and sex \\
\hline Ciliary body melanoma & & \\
1. 73-60 & JMcP & $69 \mathrm{~F}$ \\
2. 73-69 & JO'B & $76 \mathrm{~F}$ \\
3. 75-177 & EF & $63 \mathrm{~F}$ \\
$4.78-663$ & JC & $58 \mathrm{M}$ \\
$5.78-688$ & MJ & $78 \mathrm{~F}$ \\
$6.85-778$ & EJ & 50 \\
$7.85-316$ & E van B & 52 \\
Old choroiditis & & \\
8. 81-542 & JW & $60 \mathrm{M}$ \\
Neovascular glaucoma & & \\
9. 79-712 & AB & $77 \mathrm{M}$ \\
$10.80-03$ & AMcR & $66 \mathrm{M}$ \\
\hline
\end{tabular}

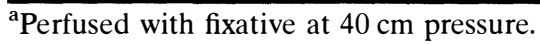

closure glaucoma have not been investigated due to successful treatment and the absence of suitable material for study. It is generally accepted that in the primary disease angle closure starts in the upper part of the chamber angle and progresses downwards. ${ }^{59}$ Thus in this condition it is likely that, as the pressure rises, the trabecular tissue will be protected where there is complete iridotrabecular contact, while in sectors where there are only narrow synechiae the meshwork will be exposed to high flow of aqueous due to the high intraocular pressure. To investigate this hypothesis, I studied the chamber angle in a group of 10 enucleated human eyes (Table I) in which there was a partial angle closure in some areas as observed in routine paraffin sections. It must be stressed that these globes were enucleated in treatment of secondary angle closure glaucoma. Blocks were taken for electron microscopy and giant vacuoles were counted in semithin sections stained with toluidine blue according to the established techniques described above.

\section{Complete Angle Closure}

In the cases in which there was angle closure as far as the peripheral cornea, the iris was compressed against the inner surface of the meshwork (Fig. 4a). The uveal and corneoscleral layers of the trabecular meshwork were also compressed, although the trabecular endothelial cells were still identifiable. In some cases Schlemm's canal was either reduced to a narrow slit or was not identifiable; giant vacuoles were never observed in these circumstances. In other cases the canal was widely dilated. In this situation, we must assume that the total abolition of flow had resulted in reflux of blood from the collector channels in which pressure was high due to episcleral congestion secondary to raised intraocular pressure.

\section{Partial Angle Closure}

In sectors in which the chamber angle was open there 


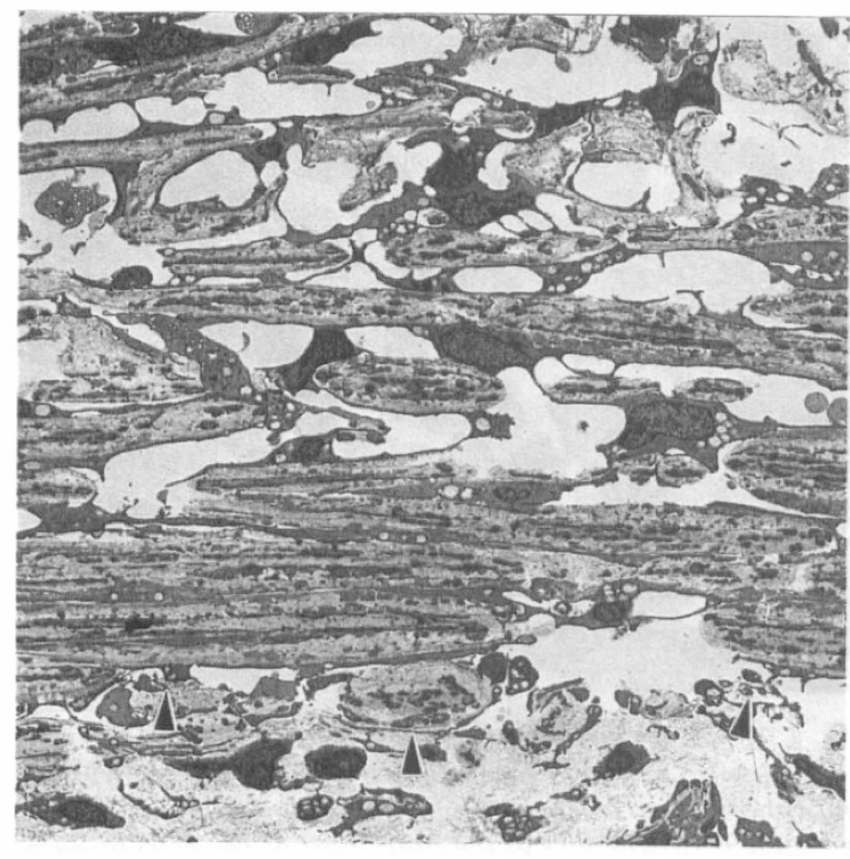

Fig. 5. Electron micrograph to show fusion between the iris stroma (arrowheads) and the uveal beams which are compressed. $(\times 100)$

were plentiful giant vacuoles in the majority of specimens (Fig. 4b). In some cases the giant vacuole counts reached values of $30-50$ per section, which was greater than that noted in the experiments on perfusion-fixed eyes. ${ }^{34}$ Where iridotrabecular contact was loose and interrupted, giant vacuoles were still present and in some cases were numerous even though the uveal trabeculae were compressed. The latter finding was not entirely consistent with the working hypothesis, but could be explained by the assumption that there was lateral diffusion of aqueous through the looser adjacent trabecular tissues. In other specimens, in which the uveal beams were compressed and fused (Figs. 4c, 5), the giant vacuoles counts were much lower than those sections in which there was obvious space for aqueous to pass into the trabecular meshwork. At the ultrastructural level it was difficult to find any space between the iris stroma and the collagenous cores of the trabeculae (Fig. 5). Uveal trabecular fusion occurred in the absence of iridotrabecular contact in some cases, which implies separation of pre-existing contact.

In two cases it was possible to identify fragments of iris stroma attached to the uveal trabeculae - a feature which could also be interpreted as an indication of separation of pre-existing synechiae (Fig. 6). Thus fragments of fibrous tissue derived from the iris stroma and firmly adherent to the inner surface of the meshwork could be responsible for obstruction to aqueous outflow.

One of the most interesting findings in terms of the effects of overperfusion was that where the angle was

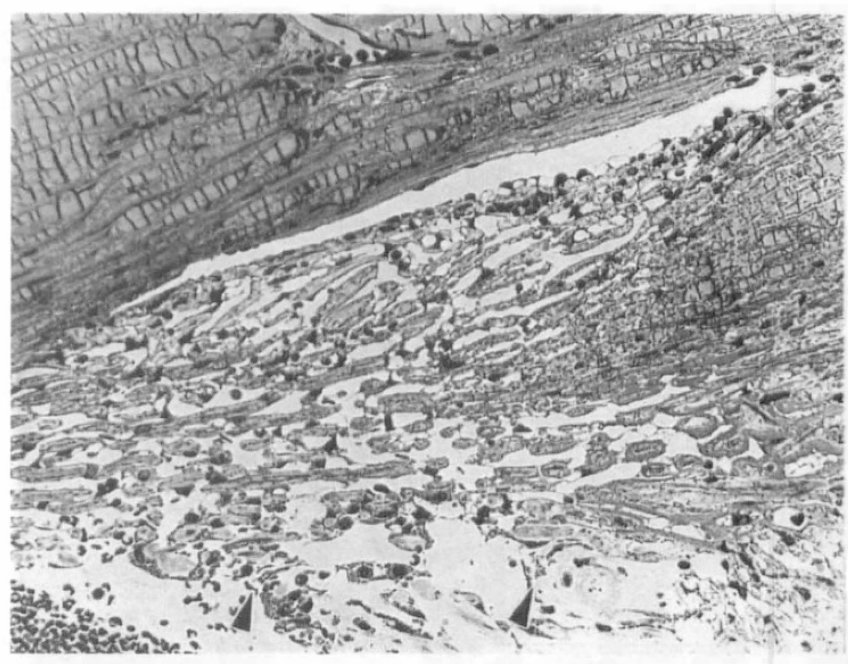

Fig. 6. Fragments of iris stroma (arrowheads) attached to the inner surface of the meshwork.

open and the uveal trabeculae were widely spaced, there was inner/outer wall apposition of the endothelium of Schlemm's canal such as was seen in the primate experiments (Figs. 2, 4d). This appeared to lead to disorganisation of the canal with residues of cellular strands linking the inner and outer walls. In one specimen it was possible to identify a bulge from the cribriform layer blocking a collector channel (Fig. 4d). The various disturbances seen in the trabecular meshwork in this series of secondary closed angle glaucoma cases could account for the well-recognised failure to control intraocular pressure by surgical iridectomy or YAG laser iridotomy in a minority of cases of primary closed angle glaucoma. ${ }^{4-6}$ An increased resistance to aqueous outflow could follow fusion of uveal trabecular beams or adherence of remnants of iris stroma to the uveal layers. More importantly, disintegration of the lining endothelium of Schlemm's canal would rob the system of the delicately controlled capability of transferring aqueous by the giant vacuole bulk flow system.

As a supplement to these conclusions, I have noted in a separate study of routine trabeculectomy specimens removed in treatment of closed angle closure unresponsive to primary intervention (iridectomy or iridotomy), the presence of inflammatory cells, usually lymphocytes, in the intertrabecular spaces. This suggests that in the acute primary form of closed angle glaucoma a rapid rise in intraocular pressure had caused ischaemia in the iris stroma. Release of inflammatory mediators (e.g. prostaglandins and prostacyclins) would promote migration of inflammatory cells into the iris stroma and the anterior chamber with subsequent migration into the intertrabecular spaces. In many of the trabeculectomy specimens the presence of numerous melanin granules in the trabecular endothelial cells was noteworthy; this could be explained by ischaemic 


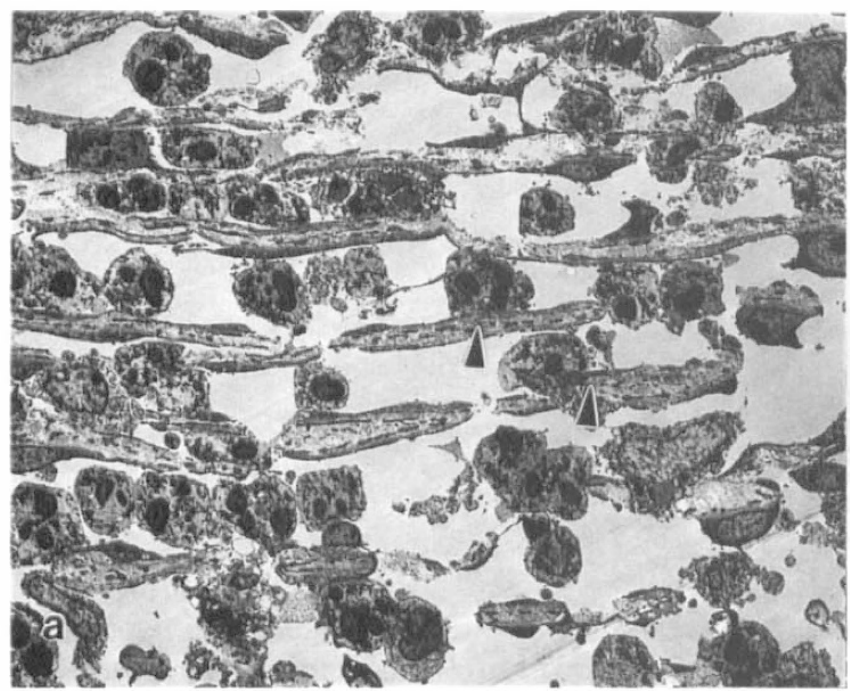

(a)

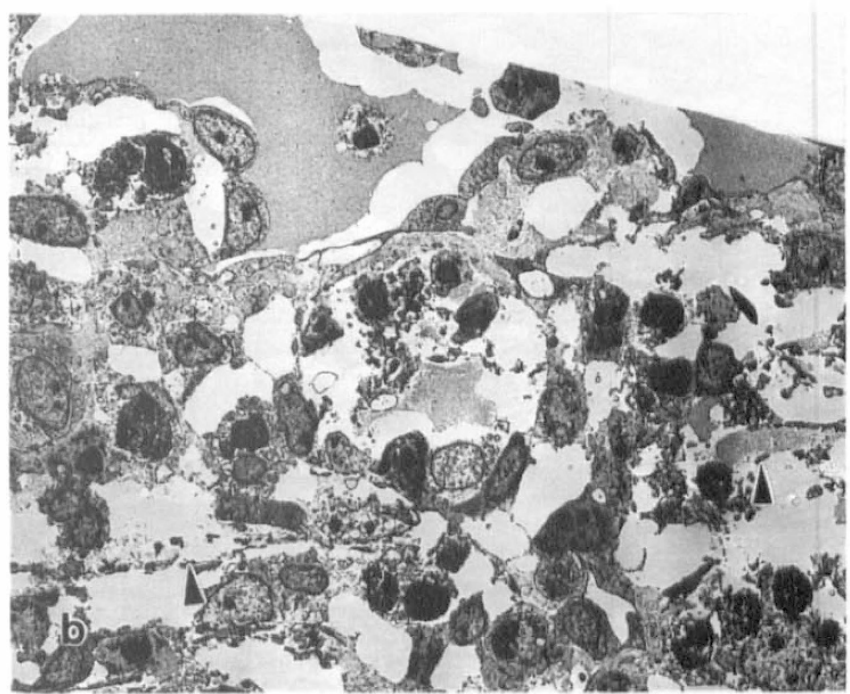

(b)

Fig. 7. Electron microscopy of polymorphonuclear leucocytes infiltrating (a) the inner part of the trabecular meshwork and (b) the outer part. In the inner part contact between dying polymorphonuclear leucocytes and trabecular endothelial cells destroys the latter (arrowheads). The dissolution of the trabecular beams (arrowheads) in the outer part of the meshwork is due to lysis of the leucocytes with release of proteolytic enzymes. $($ each $\times 1000)$

necrosis of the pigment epithelium or could have represented damage by surgical intervention or YAG laser treatment, both of which could have disrupted the pigmented cells of the iris.

The consequences of inflammatory cell infiltration and melanin overload are discussed in the following section.

\section{RESPONSE OF THE OUTFLOW SYSTEM TO CELLULAR INFILTRATION}

Amongst the various forms of secondary open angle glaucomas, those which are due to inflammatory disease are of clinical importance because of the challenges they present in terms of diagnosis and management. For the pathologist these disorders are of interest in terms of the effects of the presence of infiltrating cells on the resident cells. Although in many cases encountered in routine pathology the infiltrate is of a mixed nature, consisting of polymorphonuclear leucocytes, lymphocytes, plasma cells and macrophages, in some disorders the inflammatory response essentially involves one population of cells. While the term 'trabeculitis' should apply to all forms of cellular infiltrate, it is most commonly applied in clinical usage to lymphoplasmacytoid infiltration in chronic non-specific anterior uveal inflammatory disease.

\section{Polymorphonuclear Leucocytes: Hypopyon}

From clinical experience it would appear that the outflow system recovers effectively after exposure to polymorphonuclear leucocytes. In the case of a small hypopyon any permanent damage would be restricted presumably to the inferior part of the chamber angle and this would not have any significant effect on the functional capacity of the remainder of the outflow system. This assumption has not been investigated by pathological studies and the deleterious effects of massive infiltration of the trabecular meshwork by polymorphonuclear leucocytes has not been documented at the ultrastructural level. It could be assumed that release of proteolytic enzymes would dissolve the collagenous cores of the trabeculae if the protection afforded by the trabecular endothelial cells were lost. In the most severe example in my files there was a considerable degree of disruption of the collagenous cores where the endothelial cells had separated (Fig. 7) or had been destroyed by leucocytes in contact with the cells. In addition there appeared to be an almost total loss of matrix in the cribriform layer, presumably due to release of proteolytic enzymes by the degenerate leucocytes which were trapped there.

Detailed morphological information concerning the effects of the later stages of a pyogenic infection is also sparse because in those cases proceeding to enucleation, the rapid progress of pyogenic endophthalmitis is so destructive that ultrastructural investigation would appear unrewarding. The anterior chamber in routine histopathological preparations contains a fibrinopurulent exudate in the inferior angle and this is associated with synechia formation due to hypotonia and fibrinous adhesions between the iris stroma and the trabecular meshwork. In addition the end-stage is complicated by fibrosis of the trabecular meshwork and fibrovascular proliferation in the scleral sulcus.

\section{Lymphoplasmacytoid Infiltration (Non-Granuloma- tous Trabeculitis)}

The clinical features of all forms of non-granulomatous trabeculitis have been comprehensively 
Table II. Details of specimens used for the study of non-granulomatous trabeculitis

\begin{tabular}{|c|c|c|c|}
\hline Case no. & Patient & Age (years) and sex & Clinical details \\
\hline 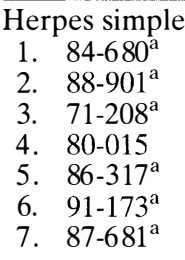 & $\begin{array}{l}\text { JMcCF } \\
\text { JB } \\
\text { TP } \\
\text { AS } \\
\text { JR } \\
\text { JW } \\
\text { CG }\end{array}$ & $\begin{array}{l}69 \mathrm{~F} \\
75 \mathrm{~F} \\
67 \mathrm{M} \\
69 \mathrm{~F} \\
70 \mathrm{M} \\
81 \mathrm{M} \\
62 \mathrm{M}\end{array}$ & $\begin{array}{l}\text { Iritis, normal IOP } \\
\text { Iritis, normal IOP } \\
\text { Iridocyclitis, hypopyon } \\
\text { Iritis, partial angle closure } \\
\text { POAG, trabeculectomy, iritis } \\
\text { Iritis, glaucoma } \\
\text { ?HSK, acid burns, keratoplasty, iritis }\end{array}$ \\
\hline $\begin{aligned} & \text { Fuchs' heteroc } \\
& 8 . 71-225 \\
& 9 . 87-735^{\text {a.b }} \\
& 10 . 92-219 \\
& 11 . 93-167\end{aligned}$ & $\begin{array}{l}\text { yclitis } \\
\text { AP } \\
\text { BT } \\
\text { RH } \\
\text { SO'B }\end{array}$ & $\begin{array}{l}60 \mathrm{~F} \\
48 \mathrm{M} \\
51 \mathrm{M} \\
38 \mathrm{M}\end{array}$ & \\
\hline $\begin{array}{l}\text { Miscellaneous } \\
\text { 12. } 82-876 \\
\text { 13. } 85-1168^{\mathrm{a}}\end{array}$ & $\begin{array}{l}\text { MD } \\
\text { MD }\end{array}$ & $\begin{array}{l}71 \mathrm{~F} \\
70 \mathrm{~F}\end{array}$ & $\begin{array}{l}\text { RD, iritis, trabeculitis } \\
\text { HZO, iritis, fibrosis of Schlemm's canal }\end{array}$ \\
\hline
\end{tabular}

IOP, intraocular pressure; POAG, primary open angle glaucoma; HSK, herpes simplex keratitis; RD, retinal detachment: HZO, herpes zoster ophthalmicus.

${ }^{a}$ Cases studied by electron microscopy.

${ }^{\mathrm{b}}$ Trabeculectomy specimen.

reviewed in many standard texts. ${ }^{4,6,60}$ The response of the outflow system to lymphocytic infiltration in anterior uveitis is said to be variable: many cases lead to hypotonia, only some to a raised pressure. ${ }^{61}$ Before the advent of effective anti-viral therapy, one of the commonest causes of trabeculitis was herpes simplex keratouveitis, and a raised intraocular pressure occurred in $28 \%$ of cases. ${ }^{62}$ Because of the striking iritis associated with keratitis and trabeculitis, the clinical diagnosis of herpes simplex keratitis is easily confirmed histopathologically but cannot be proven at the later stages by identification of viral particles at the electron microscopic level. In an early light microscopic study, Hogan et al., ${ }^{63}$ who coined the term 'trabeculitis', showed infiltration of the intertrabecular spaces by lymphocytes and plasma cells within fibrin and this has been confirmed subsequently by a number of authors (see Spen$\mathrm{cer}^{64}$ for a review). Striking lymphoplasmacytoid infiltrations are not confined, however, to herpes simplex infections, but are also a feature of herpes zoster and Fuchs' heterochromic iridocyclitis. Scleritis and episcleritis are also complicated by an intense trabeculitis. $^{65}$

The pathogenesis of cell and matrix destruction in the outflow system in trabeculitis has not been widely investigated and review articles ${ }^{66}$ are somewhat speculative. The possible mechanisms suggested for outflow obstruction in uveitis include:

1. Mechanical blockage by serum ${ }^{67}$ or plasma released from iris vessels in which the permeability had been altered by inflammatory mediators. $^{68,69}$

2. Damage to trabecular endothelial cells by enzymes or cytokines released by inflammatory cells. The surviving trabecular endothelial cells would also be required to phagocytose cell debris, which could lead to stripping of the beams, fluid movement into the trabecular collagenous core and narrowing of the intertrabecular spaces.

3. Obstruction to outflow due to mechanical blockage by the cellular infiltrate on the inner surface of the meshwork, or in the intertrabecular spaces. ${ }^{60,70}$

4. At the end-stage, sclerosis of the meshwork would be associated with an endothelial downgrowth and the formation of a hyaline membrane. ${ }^{71}$

There is no documentation to my knowledge of the ultrastructural changes occurring in the trabecular meshwork in lymphoplasmacytoid trabeculitis, nor has there been a report on the immunohistochemical characteristics of the infiltrating cells. In addition the changes occurring in the intrinsic cells have not been investigated at the ultrastructural level.

To investigate this process further, 12 surgical enucleation specimens in which trabeculitis had been reported in routine paraffin sections were retrieved from file. In this series, the commonest pathology was herpetic keratouveitis (Table II). Each of the cases in the herpes simplex group was characterised by a severe non-granulomatous iritis and a lymphocytic and plasma cell infiltrate in the trabecular meshwork. In two cases (84-680 and 88-901) the globes were normotensive; the remainder showed pathological evidence of glaucoma. This is something of a heterogeneous group since in one of the specimens there was partial angle closure (85-015) and the seventh case (87-681) was presumed to be due to herpes simplex, but was complicated by the fact that the cornea had been damaged by an acid burn and a corneal graft had been performed.

Four cases of Fuchs' heterochromic iridocyclitis were available for study and one of these was a trabeculectomy specimen (87-835). Two other miscellaneous specimens exhibiting iritis were included 

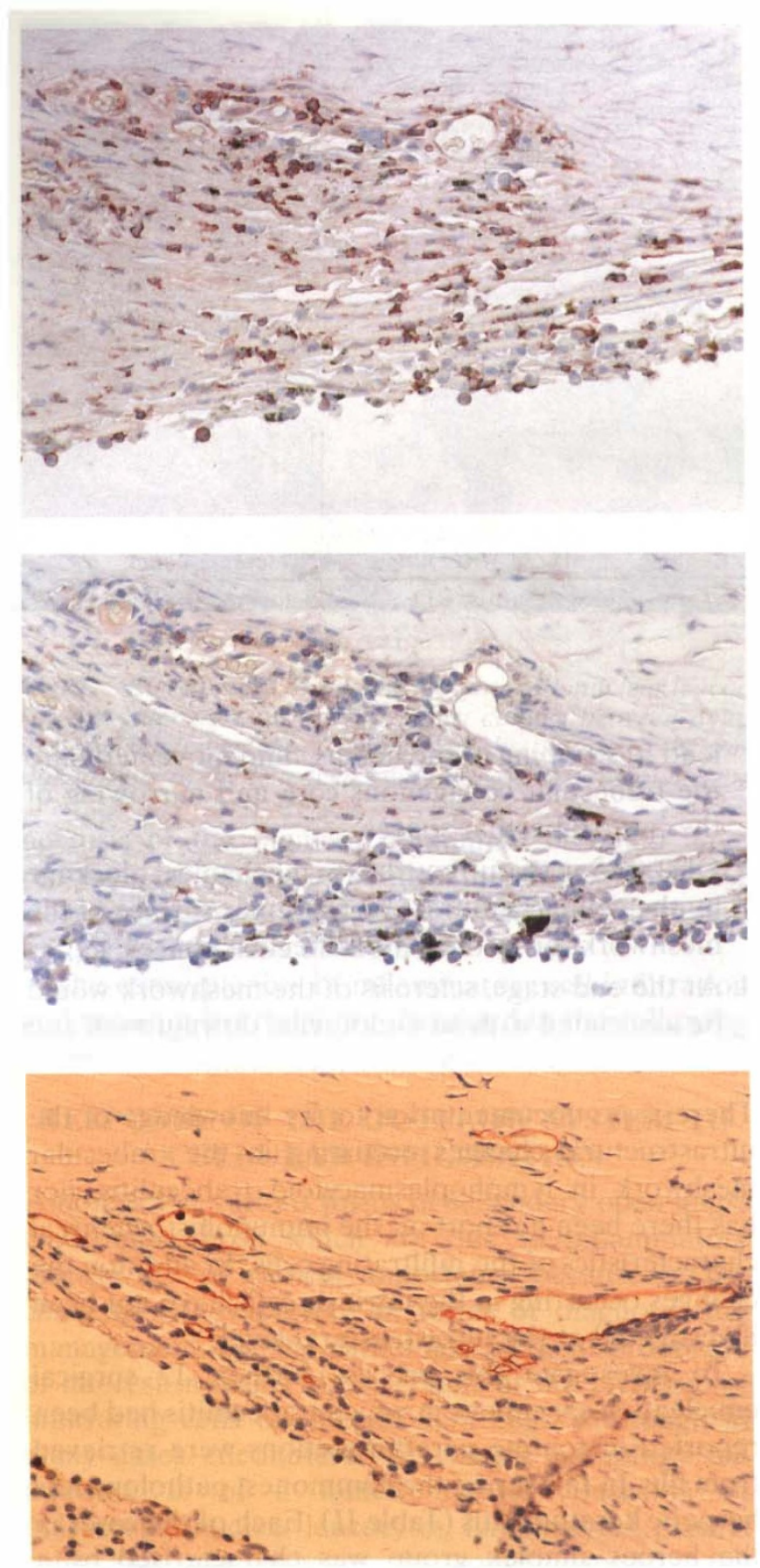

Fig. 8. Immunohistochemistry of lymphoplasmacytoid trabeculitis. The upper figure demonstrate an intense $T$ cell infiltrate. In the middle figure the marker for $B$ cells stains fewer cells which are located in the outer part of the meshwork. In the lower figure the marker for endothelial cells outlines small blood vessels within the trabeculae. The scleral sulcus is filled with fibrovascular tissue. (Original magnifications $\times 250$ )

for comparison: one a complicated retinal detachment, the other a burnt-out herpes zoster infection. Five control specimens (enucleations for posterior melanomas in patients of a similar age) were investigated using the same morphological techniques.

\section{Immunohistochemistry}

Ten of the enucleations specimens cases were subjected to immunohistochemical investigation in order to classify the constituents of the lymphocytic infiltrate. In two specimens (87-735 and 82-876) there was total fibrosis of the outflow system and immunohistochemistry was not considered to be justifiable. For T-lymphocytes, the markers employed were UCHL1 and MT1 (CD3 in some cases), and for B-lymphocytes the markers were MB1 and L26. Because there was obvious segmentation of endothelial cells in the scleral sulcus (an apparent 'neovascularisation' of Schlemm's canal) in some of the cases the following markers for endothelial cells were employed: Ulex europaeus, factor VIII antibody and Q Bend 10. The antibody reaction was visualised with ethylaminocarbimazole to avoid the confusion with melanin which occurs when the peroxidase-antiperoxidase label is used. Although the primary fixation was glutaraldehyde, the staining reactions in the tissues of the trabecular meshwork were considered reliable if there was unequivocal staining of (a) the inflammatory cells in the iris and (b) the endothelium of the blood vessels in the iris, ciliary body and conjunctiva. In general the labelling for $\mathrm{T}$ cells was more intense than for $\mathrm{B}$ cells.

In eight cases, blocks had been taken from the chamber angle and processed and embedded for electron microscopy: five cases were due to herpes simplex keratitis, one to post-'acid burn' keratitis, one to Fuchs' heterochromic iridocyclitis and one to post-herpes zoster ophthalmitis.

The results of this investigation were as follows: -

\section{Herpes Simplex Trabeculitis}

By conventional light microscopy, the most consistent pattern in less severe disease was a uniform infiltration of plasma cells and lymphocytes throughout the intertrabecular spaces, with apparent preservation of the indigenous trabecular endothelial cells: infiltration in the outer wall of Schlemm's canal was less extensive. Vacuoles were not observed in the lining endothelium of Schlemm's canal in any of the specimens. By immunohistochemistry the infiltrate was characterised by a predominant T-lymphocyte population, with only a small minority reacting with the B-lymphocyte markers (Fig. 8); such cells when present were located more commonly in the outer part of the meshwork. The trabeculae were lined by attenuated endothelial cells and there was only occasional evidence of melanophagocytosis. The lymphocytes in the iris labelled strongly for both B and $\mathrm{T}$ cells; the former were more diffuse, the latter in focal clusters.

By electron microscopy, lymphocytes and plasma cells were prominent and often occupied the surface 


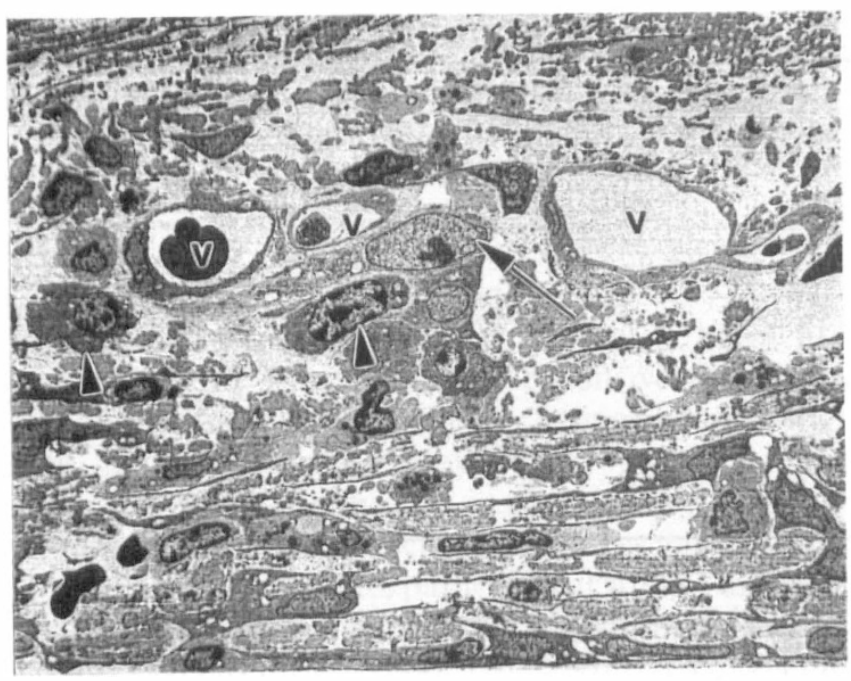

Fig. 9. Electron micrograph of the scleral sulcus in advanced trabeculitis. Note the atypical blood vessels (v) without cytoplasmic pegs to the abnormal underlying collagenous connective tissue. Note the fibroblast (arrow) and the plasma cells (arrowheads). (× 1200)

of denuded uveal trabeculae, which did not appear to be swollen. Thin trabecular endothelial cells containing occasional melanin granules lined the intertrabecular spaces, but there was no indication of phagocytosis of cell debris by these cells. Degenerative or cytolytic changes were not observed in the trabecular endothelial cells and fibrin and cell debris was not identified in the intertrabecular spaces. Viral particles were not seen in the tissues.

In the more severely affected tissue the inner part of the trabecular meshwork became compressed, although there was no striking loss of endothelial cells nor were the trabecular beams excessively swollen. More significantly, the extracellular matrix

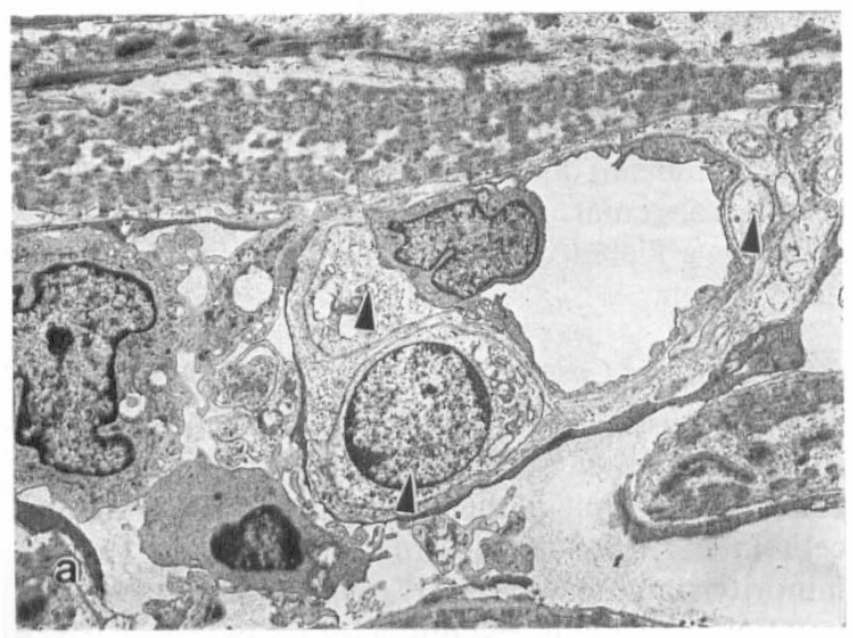

(a) in the cribriform layer and the outer wall became altered with the replacement of the normal heterogeneous mixture of fine collagenous matrix, elasticlike material and curly collagen by a fine network of fibrillar material (Fig. 9). The normal, rather stellate cells of the cribriform layer were replaced by enlarged spindle cells, which had the characteristics of fibroblasts with prominent rough endoplasmic reticulum (Fig. 9). The endothelial cells lining Schlemm's canal did not possess the pegs and attachments normally found in the lining endothelium of Schlemm's canal and the sulcus in advanced disease was often filled by a series of capillary-like structures surrounded by fibrous tissue. Giant vacuoles were never observed and there was no evidence of cell migration through the endothelial monolayer. In parts of the meshwork there was fusion of swollen trabeculae and in this circumstance the endothelial cells became swollen and formed circular capillary-like structures (Fig. 10) with a basement membrane. It was possible to identify cells resembling pericytes surrounding the endothelial cells in some examples.

These capillary-like structures were found throughout the uveal and corneoscleral layers of the meshwork in the five herpes simplex cases and in the herpes zoster case using immunohistochemical markers for mesoderm-derived endothelial cells (Table III). In keeping with the reports in recent literature, ${ }^{8,72}$ the cells lining the wall of Schlemm's canal were found to react in a similar manner to the other mesoderm-derived endothelial cells within the eye (Fig. 8c).

The interpretation of this form of vascularisation occurring within the trabecular meshwork can only be speculative at this stage. What seems unlikely

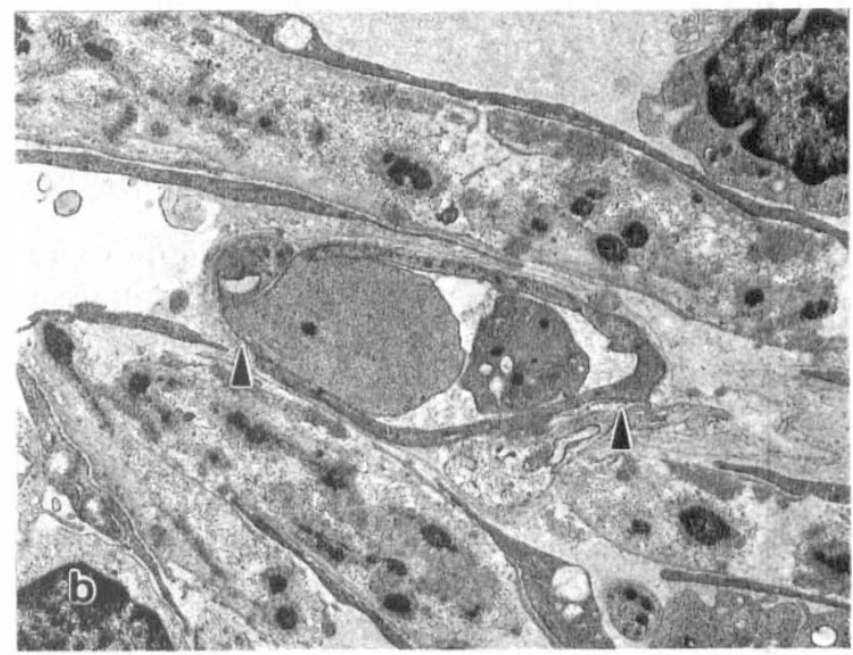

(b)

Fig. 10. Abnormal blood vessels in the intertrabecular spaces in trabeculitis. In (a) the endothelial cells are surrounded by prominent pericytes (arrowheads); in (b) the structure appears to be formed from endothelial cells (arrowheads). (Transmission electron micrographs; $a, \times 3200 ; b, \times 4700)$ 
Table III. Immunohistochemical results in trabeculitis

\begin{tabular}{lcccc}
\hline Case no. & Age (years) and sex & Vascular proliferation in meshwork & T-lymphocytes & B-lymphocytes \\
\hline Herpes simplex & $69 \mathrm{~F}$ & & & + \\
$84-680$ & $75 \mathrm{~F}$ & ++ & ++ & + \\
$88-901$ & $69 \mathrm{~F}$ & + & +++ & + \\
$85-015$ & $70 \mathrm{M}$ & +++ & ++ & + \\
$86-317$ & $81 \mathrm{M}$ & - & + & + \\
$91-173$ & & & & + \\
Acid burns & $62 \mathrm{M}$ & - & + & + \\
$87-681$ & $51 \mathrm{M}$ & & & + \\
$\begin{array}{l}\text { Fuchs' heterochromic iridocyclitis } \\
92-219\end{array}$ & & + & + \\
$\begin{array}{l}\text { Herpes zoster } \\
85-1168\end{array}$ & $70 \mathrm{~F}$ & + & + \\
\hline
\end{tabular}

from the distribution of these channels is that they were derived from a neovascular membrane on the inner surface of the meshwork. It also seems unlikely that the vessels represent extensions from the newly formed fibrovascular tissue in the scleral sulcus, because the endothelial cells in these vascular channels were not accompanied by pericytes. A more plausible suggestion is that the new capillaries were derived from ingrowths from the capillary bed in the ciliary muscle.

The morphological results obtained in the tissue of the presumed herpes simplex case (87-681) were far less impressive than those in which there was definitive clinical information to incriminate herpes simplex, so to some extent this 'non-specific' case serves as a control and this reinforces the pattern seen in herpes simplex trabeculitis.

The results of this investigation can be considered in relation to the rapidly expanding understanding of the immune recognition system in the trabecular meshwork. ${ }^{9,73-78}$ It is now evident that the tissue is an immunological filter with a resident population of cells in the meshwork capable of HLA class II antigen presentation. ${ }^{73-75}$ The upregulated recognition system in normal trabecular endothelial cells could also amplify the activity of the dendritic cells which are now known to be resident in the iris and the trabecular meshwork of the human and lower mammals. $^{76}$

In the context of viral infection, the herpes virus has the capacity to upregulate resident cells in tissue to express HLA class II through the release of gamma-interferon which also stimulates resident macrophages to produce cytokines of various types. ${ }^{7}$ Gamma-interferon (G-IFN) is a protein that has been shown to induce class II major histocompatibility antigens which inhibit normal and transformed cell proliferation and modulate macrophage activation including inhibition of phagocytosis: this is effected by disturbing the actin cytoskeleton of the cells. The immune recognition system in herpes simplex infection also has the potential of presenting antigen to $\mathrm{T}$ cells which are then stimulated to secrete cytokines (e.g. interleukin
2) which stimulate migration and proliferation of further generations of $\mathrm{T}$ cells. T-lymphocytes release a wide spectrum of lymphokines and adhesion molecules which in addition to the induction of Blymphocyte activity can modify the phenotypic characteristics of cells and hence their behaviour. It is known that B-lymphocytes are a source of interleukin 1-alpha and interleukin 1-beta, both of which stimulate fibroblastic activity (fibroblast proliferation in the scleral sulcus was one of the most interesting observations made by electron microscopy in the present study). The B-lymphocytes which were identified in the outer part of the meshwork could therefore be responsible for the stimulation of fibroblastic activity in the scleral sulcus. Alternatively, fibroblastic activity and endothelial cell proliferation could be due to the presence of growth factors such as transforming growth factor beta, known to be present in aqueous. $^{77}$ Trabecular endothelial cells have been shown to possess receptors for transforming growth factor beta and it could be aberrations in this pathway which lead to the fibrous replacement of the canal which is so common at the end-stage of a variety of disease processes. Finally, it was encouraging to discover that the presence of lymphocytes and plasma cells in the meshwork did not appear to cause significant deleterious changes in the cytoplasm of the trabecular endothelial cells. Thus, in the less severely affected cases, the trabecular beams were not swollen.

\section{Miscellaneous Cases}

The only useful information derived from the two cases included as 'miscellaneous' was that in herpes zoster ophthalmicus the predominant inflammatory cells in the meshwork were T-lymphocytes (with a minority staining with the B markers) and there was immunohistochemical staining for mesoderm-derived endothelial cells. The vascular proliferation within the trabecular endothelial cells is obviously a manifestation of a response to the abundant lymphoplasmacytoid infiltration in the meshwork in herpes simplex and in herpes zoster, but I have no 
useful information to offer for the actual nature of the immunological signalling system. Modern molecular pathology, however, will have the capability to solve this problem in due course.

\section{Heterochromic Iridocyclitis}

The clinical features of heterochromic iridocyclitis have been the subject of comprehensive reviews in the recent literature. ${ }^{78,79}$ In discussing the aetiology and pathogenesis, La Hey et al. ${ }^{80}$ came to the conclusion that the disease is a secondary phenomenon with a spectrum of clinical features and multiple causes. In the literature, pathological studies are rare, but there is general agreement that the inflammatory round cell infiltrate is not as massive as in other forms of trabeculitis and that at the end-stage intractable glaucoma is due to trabecular fibrosis and in some cases neovascular glaucoma. ${ }^{78,81,82}$

In my own collection, in two specimens of heterochromic iridocyclitis, the meshwork contained a scattered inflammatory cell infiltrate (Fig. 11) which on immunohistochemical analysis proved to be a mixed $\mathrm{T}$ and $\mathrm{B}$ cell population. This was of a different pattern and present to a far lesser degree than the inflammatory cell infiltration seen in herpes simplex keratitis. There was no evidence of capillary buds within the trabecular meshwork. A puzzling feature was that in these specimens pigment deposition was not particularly noticeable in the meshwork; this is surprising in view of the atrophy of the iris pigment epithelium and stroma which occurs in the disease. In two cases the meshwork was fibrotic and in one there was an endothelial downgrowth, which reinforces the clinical observations concerning the difficulty in management of glaucoma in heterochromic iridocyclitis. $^{4,5,6,78,79}$ Indeed, total replacement of the

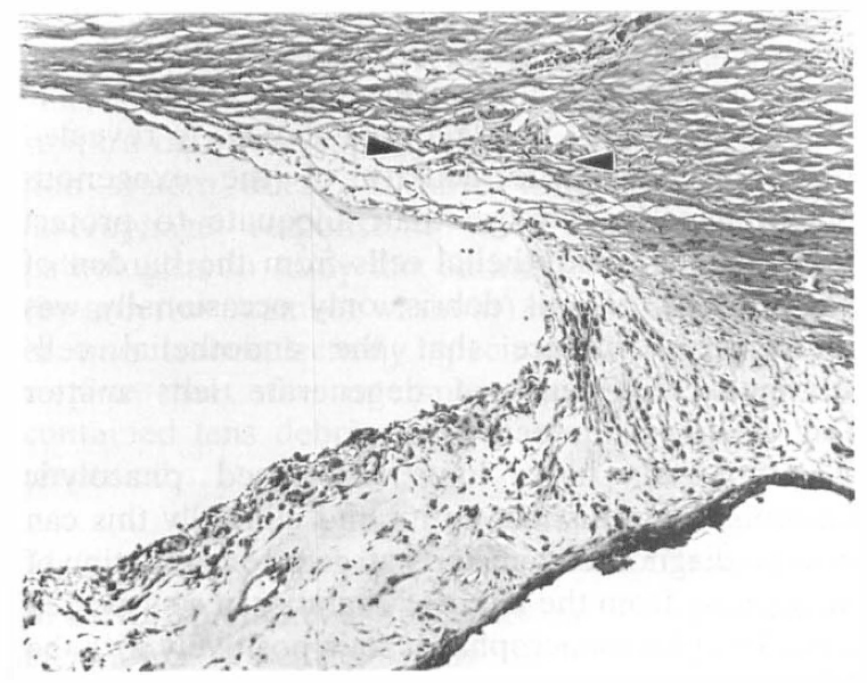

Fig. 11. In Fuchs' heterochromic iridocyclitis the inflammatory infiltrate is sparse in both iris and meshwork; fibrosis begins in the outer part of the meshwork (arrowheads). (Paraffin section, $H \& E, \times 70$ ) trabecular meshwork by dense fibrous tissue is almost a pathognomonic histopathological feature of this condition.

\section{Steroid Glaucoma}

It must be assumed that many of the cases of trabeculitis were treated with steroids and this raises the interesting question of steroid-induced resistance in the outflow system. Morphologists have not been able to provide definitive morphological evidence to explain the increased resistance in steroid glaucoma. In two studies, ${ }^{83,84}$ plaques of fibrillar material were found within the outer part of the cribriform layer, but few other authors have been able to confirm this and in my own material I have made the morphological diagnosis of corticosteroid glaucoma on only one occasion. The effects of steroids on the trabecular meshwork cells in vitro have been studied extensively, particularly with regard to secretion of extracellular matrix. ${ }^{85-90}$ Such studies have shown that the cultured endothelial cells become enlarged with an increase in smooth endoplasmic reticulum and rough endoplasmic reticulum which is in keeping with a demonstration of synthesis of, for example, glycosaminoglycans, fibronectin, collagen and elastin. Proliferation and phagocytic activity are reduced in the presence of steroids in vitro, but the relationship between this and altered function in vivo is not clear.

\section{Obstruction of the Intertrabecular Spaces by Macrophages}

For the morphologist the most visually attractive infiltration of the meshwork is that seen when a macrophagic response is activated: the mononuclear cells are large and easily seen by all forms of microscopy due to the presence of phagocytosed material. The interest for immunologists is that this

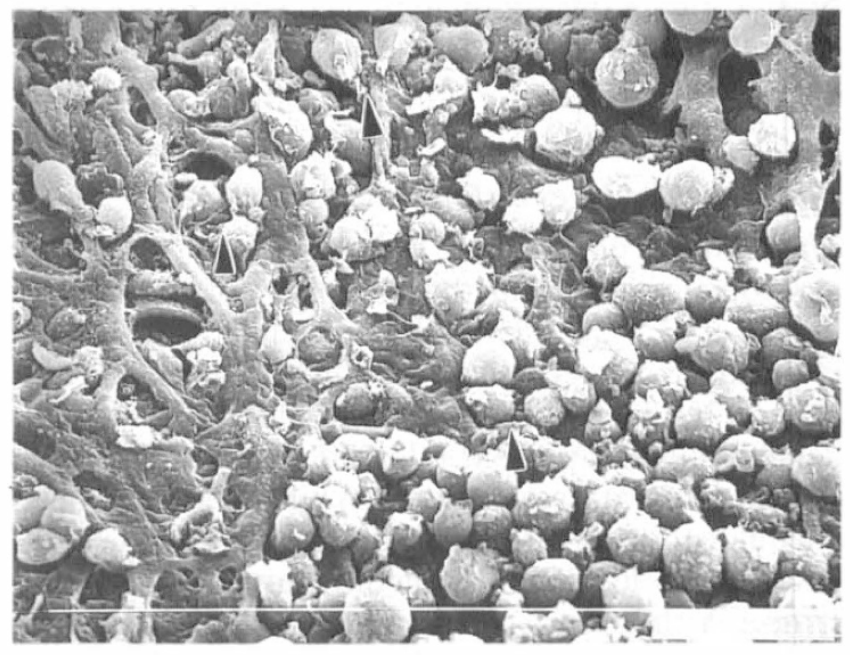

Fig. 12. In phacolytic glaucoma large spheroidal macrophages line the inner surface of the meshwork and block the intertrabecular spaces (arrowheads). (Scanning electron micrograph, $\times 670)$ 


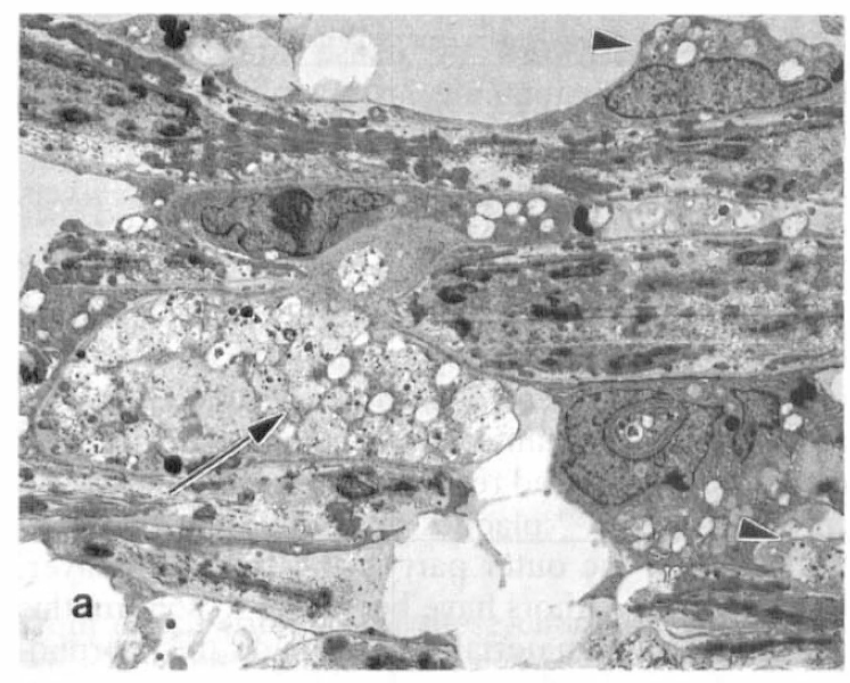

(a)

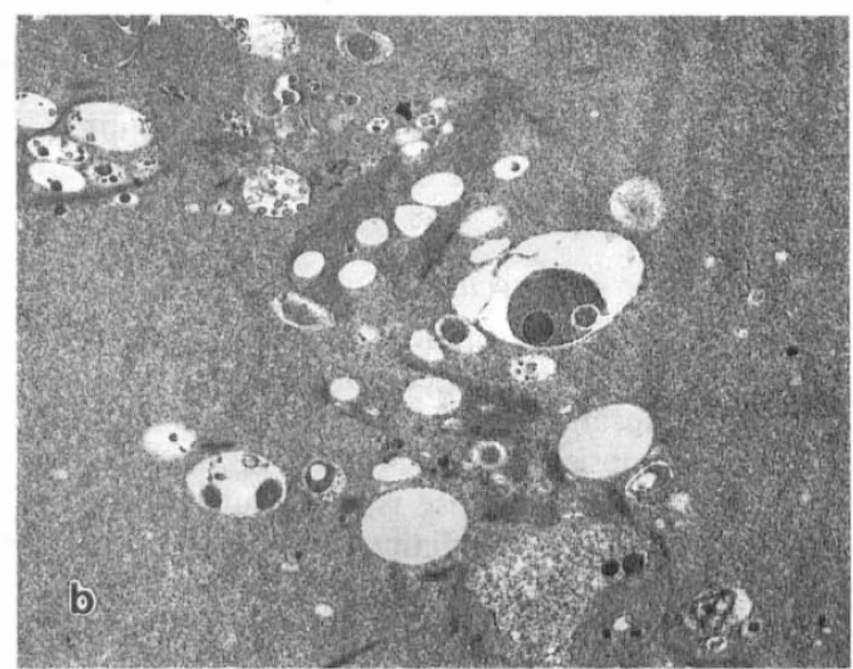

(b)

Fig. 13. In (a) a phacomacrophage is jammed in an intertrabecular space (arrow); small clumps of lens matter can be identified in the cytoplasm of the endothelial cells (arrowheads). In (b) the electron micrograph demonstrates the wide variety of abnormal structures present in a degenerating lens cortex; these can be seen in the phacomacrophages. (a, $\times 3000 ; b$, $\times 10000)$

response does not apparently involve the lymphoplasmacytoid arm of the antigen recognition system. The macrophagic reaction to endogenous particulate material may be a simple chemotactic response as has been shown to occur in in vitro experiments in which lens protein acts as a chemoattractant to suspensions of macrophages. ${ }^{91}$ This begs the question as to how the recognition arm of the reaction (see the section on lymphoplasmacytoid infiltration) is primed to 'call up' the monocytes which enter the anterior chamber via the iris vasculature.

Clinical entities in which a massive macrophagic reaction is triggered by the immune detection system in the outflow system are seen when the aqueous fluid contains lens matter (phacolytic glaucoma), melanosomes (melanomalytic glaucoma) and blood with its breakdown products (haemomacrophagic glaucoma).

\section{Phacomacrophages in Phacolytic Glaucoma}

The clinical entity now recognised as 'phacolytic glaucoma' was identified at the pathological level by Flocks et al. ${ }^{92}$ in 1955 . This paper demonstrated the importance of mechanical obstruction of the outflow system by macrophages which had phagocytosed degenerate lens protein released from the liquefied cortex of a cataractous lens. While there has been adequate documentation subsequently at the light microscopic level, ultrastructural investigations are sparse. With Professor Grierson, I studied three cases of phacolytic glaucoma (unpublished data) with the purpose of investigating the involvement of the trabecular endothelial cells in the phagocytic process. What was apparent by scanning and transmis- sion electron microscopy was that the enlarged macrophages completely blocked the interspaces in the inner part of the meshwork and that there was very little infiltration into the outer part of the meshwork (Figs. 12, 13a). This was because the cells were presumably too large to insinuate themselves through the intertrabecular spaces. Thus it would seem unlikely that washout of the anterior chamber would relieve this form of obstruction once established.

In these specimens there was no evidence of cell debris which could represent fragments of degenerating lens cells lying loose in the intertrabecular spaces. The cytoplasm of the macrophages contained globules, membrane-bound vesicles and granular bodies identical to those which are found in the degenerating lens fibres (Fig. 13b) in the senile human cataract. ${ }^{93-96}$ Electron microscopy revealed that the phagocytic activity of the exogenous macrophages was more than adequate to protect the trabecular endothelial cells from the burden of phagocytosis of lens debris; only occasionally was there any evidence that the endothelial cells contained fragments of degenerate lens matter (Fig. 13a).

Pathologists have long recognised phacolytic glaucoma as a distinct entity and clinically this can now be diagnosed at an early stage by examination of an aspirate from the anterior chamber in a suspected case. The phacomacrophages stain positively with the PAS stain and react positively with immunohistochemical markers for macrophages. ${ }^{97}$

It should also be noted that crystalline material is present too in such preparations and examination 


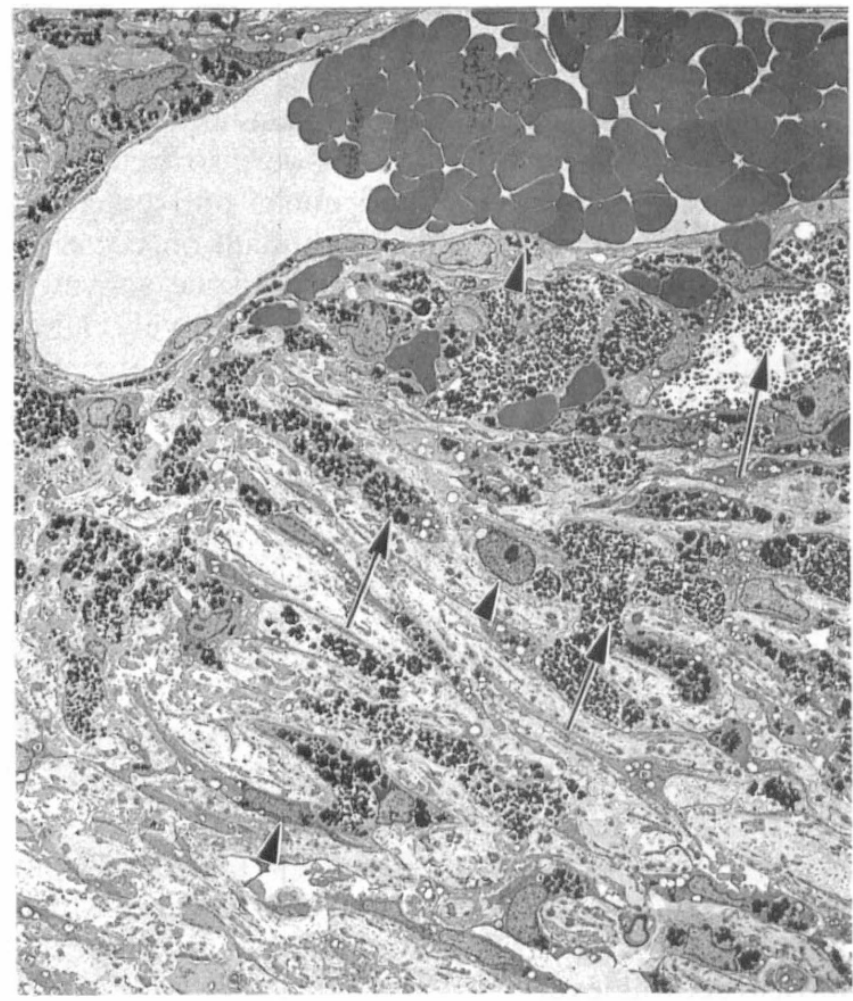

Fig. 14. Melanomacrophages (arrows) infiltrating the outer part of the meshwork in a case of melanomalytic glaucoma; trabecular endothelial cells and the endothelial cells lining the canal also contain melanosomes (arrowheads). (Transmission electron micrograph, $\times 2400)$

will reveal the presence of birefringent calcium oxalate which is commonly observed in the sclerotic nucleus of a Morgagnian cataract. The biochemical derivation of calcium oxalate in a nuclear cataract is unexplained, as is the identification of the cholesterol crystals which have also been observed in the aspirate. ${ }^{97}$

Both morphologists and clinicians must take note that the outflow system can be blocked by lens protein or degenerate lens matter in the absence of a macrophagic response. Presumably the capsular rupture occurs so rapidly that the immune recognition system does not have time to recruit the macrophage response. ${ }^{98,99}$ The opportunity for pathologists to study this eminently curable disease (by anterior chamber washout) is of course rare, but in one trabeculectomy specimen I was able to confirm that the interspaces of the meshwork contained lens debris only: macrophages were not identified.

\section{Melanomacrophages in Melanomalytic Glaucoma}

Massive spontaneous necrosis in a ciliary body melanoma, a ciliary body melanocytoma or a choroidal melanoma leads to release of myriads of melanin pigment granules into the anterior chamber and an acute rise in intraocular pressure. In one case on file ${ }^{100}$ we found that the outflow system was

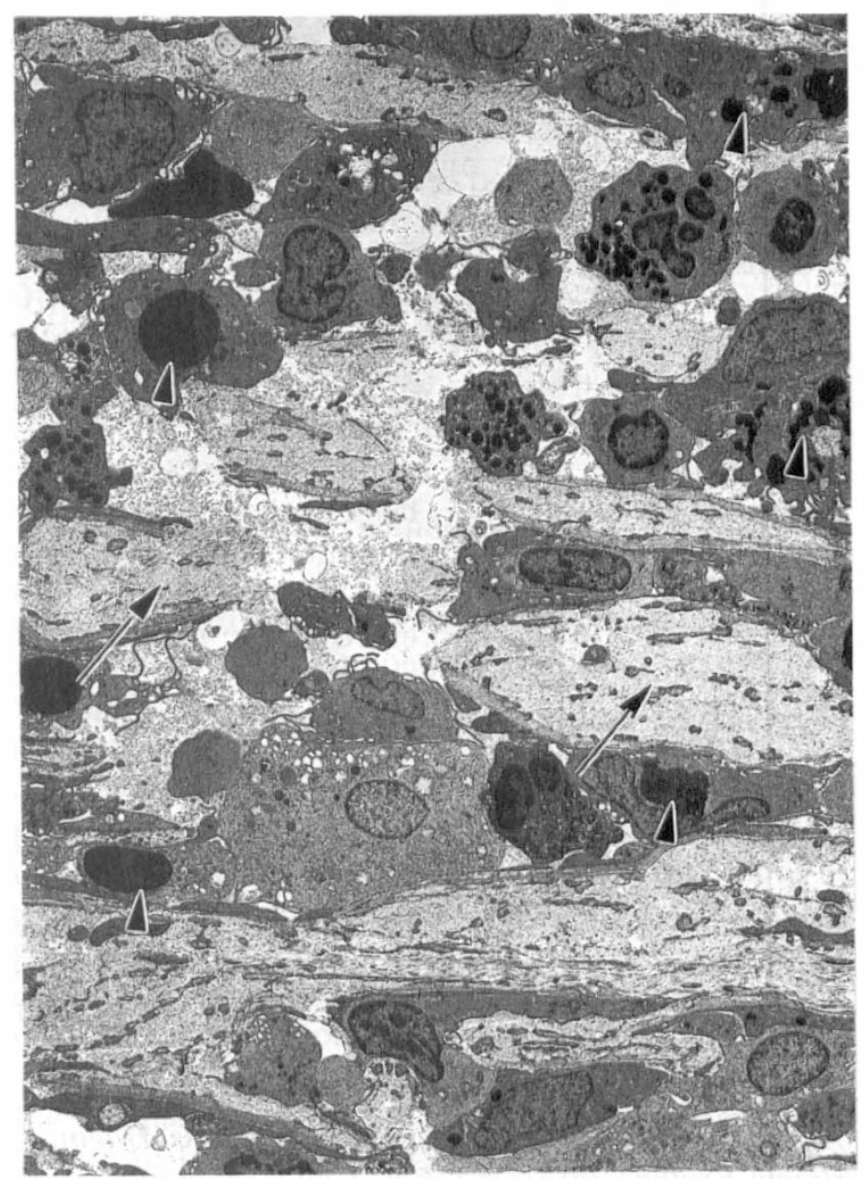

Fig. 15. Intact and fragmented red cells (arrowheads) are present in the cytoplasm of macrophages after prolonged exposure to bleeding into the anterior chamber. Where the endothelial cell cover is lost, the trabecular beams are swollen (arrows). (Transmission electron micrograph, $\times 2000)$

packed with extremely large macrophages containing primary and secondary melanophagosomes (Fig. 14). There was only a moderate quantity of melanophagocytosis in the trabecular endothelial cells, which could be interpreted to mean that the melanosomes released from the necrotic tumour were already phagocytosed before the trabecular endothelial cells could be exposed to the particles. The activated endothelial cells bear some resemblance to neoplastic cells and this is relevant to the fact that melanomalytic glaucoma is not an altogether benign process since it has been possible to demonstrate viable tumour cells interspersed between the macrophages by use of an immunohistochemical marker such as S-100 and by electron microscopy. ${ }^{100,101}$ While melanomalytic glaucoma is an entity always included in standard texts, it is a great rarity in clinical and pathological practice and rather surprisingly it has not been found to occur in proton beam treated melanomas, in which there is much more tumour necrosis than is usually seen after other forms of therapeutic irradiation. 


\section{Glaucoma Occurring in Response to Intraocular Haemorrhage}

Haemomacrophages

Although malleable red cells can pass easily through the outflow system in small numbers in experimental models, ${ }^{102}$ it has long been recognised that the outflow system is obstructed when there is prolonged bleeding into the anterior chamber. ${ }^{103} \mathrm{Red}$ cells break down readily with disruption of the cell membrane and release of haemoglobin fragments. The cell fragments are eagerly phagocytosed by macrophages and these large cells obstruct the intercellular spaces in combination with fibrin and non-phagocytosed cell debris. In our own initial studies $^{104,105}$ we were impressed by the involvement of trabecular endothelial cells in the phagocytic process and it was attractive to postulate that the activation of the endothelial cells leads to their separation from the trabecular beams and their migration out of the system. Loss of endothelial cells by this process of stripping was thought to be important in that the collagenous cores became swollen by the absorption of aqueous and this could lead to a narrowing of the intertrabecular spaces (Fig. 15).

Blood Products Released from a Vitreous Haemorrhage: Erythroclastic or Ghost Cell Glaucoma

Haemomacrophagic obstruction of the outflow system is less significant when blood passes through the vitreous face after a long-standing vitreous haemorrhage. In this situation, incarcerated red cells undergo spontaneous lysis with the passage of time and assume a spherical shape which endows the property of rigidity. Release of such cells into the anterior chamber causes a transient glaucoma which can be diagnosed by the presence of lysed red cells or 'ghost' red cells in an aqueous tap. The term 'ghost cell glaucoma' is appropriate for this process, although 'erythroclastic glaucoma' is an acceptable alternative. ${ }^{106}$ In my own files it has not been possible to find a completely monocellular ghost cell infiltrate in the trabecular meshwork and there has always been an admixture of macrophages in cases of such severity that enucleation has been required.

\section{Invasion by Neoplastic Cells}

The many mechanisms which lead to glaucoma in an eye containing a malignant uveal tumour have been reviewed by Shields et al. ${ }^{10}$ In terms of the biology of the trabecular meshwork it is necessary to consider only the effects of tumour cell infiltration on the endothelial cells. My own studies of neoplastic melanocytic infiltration of the trabecular meshwork have been confined to ring spread in iris melanomas and ciliary body melanomas. While tumour cells, identified by the presence of premelanosomes in the cytoplasm, were present in the interspaces of all layers of the meshwork, there was no evidence of damage or degeneration in the trabecular endothelial cells. Indeed the endothelial cells were so 'activated' that the presence of enlarged nuclei and phagocytosed melanin granules made it difficult on occasion to distinguish the malignant cells from the activated normal cells. In four cases in a relatively large personal series of 60 iris melanomas there was evidence of spread into Schlemm's canal, but this did not appear to result in a greater risk of metastatic death: none has been recorded as yet after 5-10 years. It is, however, important to note that in a small proportion of cases, iris melanomas if left in situ will transform into cells which have a much more malignant phenotype with the appearance of large epithelioid cells. ${ }^{108}$

While there is obvious damage to the meshwork cells in the pseudohypopyon produced when a necrotic retinoblastoma releases debris into the anterior chamber, there is to my knowledge no available information concerning the changes which are observed in the trabecular endothelial cells at the ultrastructural level.

\section{OBSTRUCTION OF THE OUTFLOW SYSTEM BY ABNORMAL EXTRACELLULAR MATERIALS}

The importance of the phagocytic activity of the trabecular meshwork in maintaining the aqueous outflow pathway by clearing obstructive debris and particulates from the channels has already been discussed. Pathological investigations and in vitro studies have shown that the trabecular endothelial cells in the natural environment are facultative and highly discriminatory phagocytes which can remove endogenous particulate material such as melanin granules and the breakdown products of blood from the aqueous. It has been suggested that overload of the self-cleansing biological filter mechanism may contribute to the pathogenesis of certain types of obstructive glaucomas. ${ }^{40}$ The intrinsic natural particles to be included in this context are red cell fragments and lens debris (see above), melanosomes, and exfoliation material. The non-biological exogenous materials to be considered include emulsified silicone oil and Haelon. The latter, however, causes only transient glaucoma when used in cataract surgery and to my knowledge this cause of a raised intraocular pressure has not been investigated by morphology in human tissue.

In the various pathological situations, an overload of the system can have very serious consequences in terms of the functional and anatomical preservation of the tissue. However, in some circumstances the system has a surprising capacity for recovery, as in some forms of pigmentary glaucoma. 


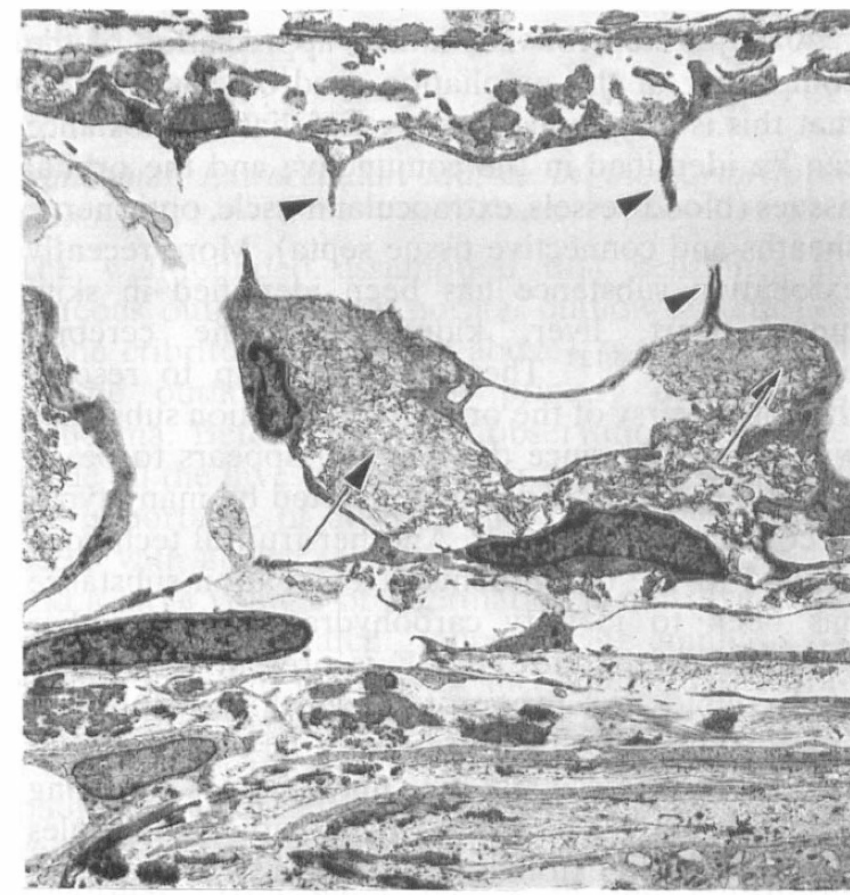

Fig. 16. Exfoliation material in the cribriform layer appears to invaginate the endothelial cells (arrows). Note the strands of endothelial cells crossing the canal (arrowheads) which suggests previous inner/outer wall contact. (Transmission electron micrograph, $\times 3000$ )

\section{Pigmentary Glaucoma}

The clinical and pathological features of aqueous outflow obstruction due to overload by melanin granules have been reviewed comprehensively. ${ }^{109,110}$ The main source of free melanosomes in the pigmentary glaucomas is the iris pigment epithelium, but pigment may be released also from the heavily pigmented iris stroma. Thus any form of damage to the iris stroma (e.g. contusion angle deformity) can lead to pigment deposition in the meshwork; indeed such deposition is a feature of the normal ageing process in some individuals when it is due to iris atrophy. More extensive deposition can occur after lens surgery when the monolayer is damaged by removal of a cataractous lens and insertion of an implant, but as a secondary phenomenon trabecular endothelial pigmentation is striking in the exfoliation syndrome, in which there is progressive breakdown of the iris pigment as the exfoliation substance accumulates within the cells and on the surface. The most impressive accumulation of melanin in the trabecular endothelial cells occurs in the pigment dispersion syndrome and in pigmentary glaucoma, two conditions in which the aetiology is unknown. There are many unexplained clinical features such as the rarity in Asians and blacks and the clinical observation that sometimes in pigmentary glaucoma the trabecular meshwork is not pigmented even though there is a Kruckenberg spindle. Paradoxically, good experimental evidence has been obtained to show that pigment granules per $s e$ within the extracellular spaces of the meshwork do not contribute significantly to resistance. ${ }^{111}$

Histopathological and electron microscopic investigations have been in agreement that after a massive overload of melanin granules to the trabecular endothelial filtering system, there is separation of the endothelial cells and collapse of the trabecular meshwork. ${ }^{112-116}$

\section{(Pseudo)exfoliation Glaucoma}

The clinical ${ }^{6,117}$ and conventional pathological features $^{64,118}$ of the 'pseudo' exfoliation syndrome are well documented. In paraffin sections, exfoliation substance appears as eosinophilic amorphous clumps on the ciliary processes, the zonular fibres, the anterior lens capsule and on both anterior and posterior surfaces of the iris. The morphological demonstration of a dense deposition of exfoliation substance in the cribriform layer and on the inner surface of the meshwork goes some way towards explaining why the response to pilocarpine is less effective in the exfoliation syndrome. ${ }^{119}$

Electron microscopy is required to demonstrate the fibrillar nature of the material, ${ }^{118}$ which in some cases can be identified within giant vacuoles in the lining endothelium of Schlemm's canal (Fig. 16). Few authors have been able to confirm the original observations by Ringvold ${ }^{120}$ that the trabecular endothelial cells have the capacity to phagocytose exfoliation substance. In my own cases, the trabecular endothelial cell morphology has been well preserved without evidence of intracytoplasmic exfoliation substance. The electron microscope is also required to demonstrate exfoliation substance in the walls of iris vessels, which are extensively altered in the disease process, ${ }^{121}$ so much so that some authors have suggested that deposition at this site leads to a lowering of the oxygen tension in the aqueous, which could potentially have a serious effect on the viability of the trabecular endothelial cells. $^{122}$

In addition to the nomenclature ('pseudo' or 'nonpseudo-' exfoliation), controversies persist in many aspects of this disease. For a pathologist, the site of origin (or synthesis) and the biochemical composition of exfoliation substance remains a major challenge. For the clinician, the extent to which exfoliation substance deposited in the outflow system contributes to resistance in open angle glaucoma is not yet defined. ${ }^{6,117}$ Undoubtedly in some parts of Europe, such as Greece, the disease is common and constitutes a major part of the practice of a specialist in glaucoma. ${ }^{117}$ In addition, the management of open angle glaucoma in cases in which the exfoliation deposits are prominent and heavy, can be more 


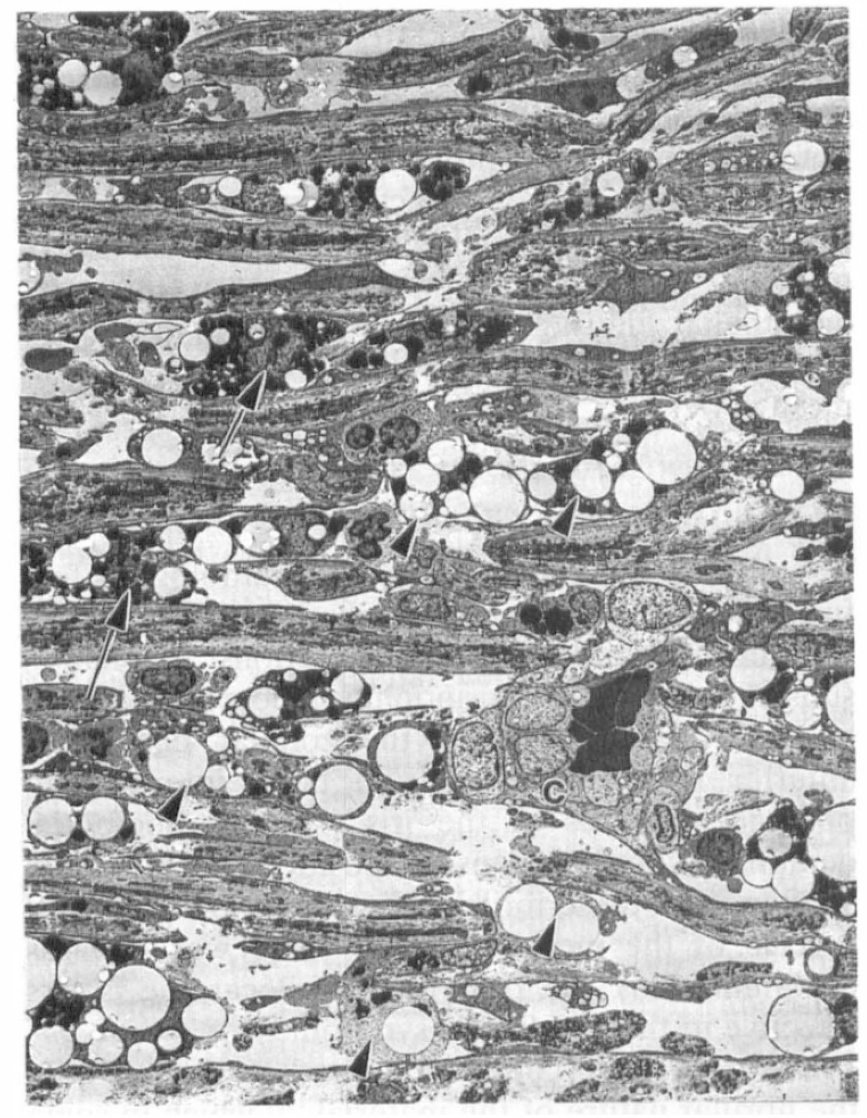

Fig. 17. Silicone oil droplets in the cytoplasm of macrophages in the intertrabecular spaces (arrowheads). Some of the macrophages also contain intracytoplasmic melanosomes (arrows). This unusual specimen also contains a capillary (c) in the intertrabecular space. The tissue was taken from a glaucomatous eye after treatment of retinal detachment using intravitreal silicon. (Transmission electron micrograph, $\times 1000)$

difficult than in cases of primary open angle glaucoma.

Histochemistry and immunogold electron microscopy have been useful tools in the identification of the constituents of exfoliation substance and the groups led by Streeten, ${ }^{118,123,124}$ Schloetzer-Schrehardt $^{125-127}$ and Konstas ${ }^{121,128,129}$ have made major contributions in this field. To date the following substances have been identified within exfoliation substance: elastin-related proteins (e.g. elastin), ${ }^{123,124}$ fibrillin, amyloid $\mathrm{P}^{129} \mathrm{gp} 115$ (an elastin-related glycoprotein), ${ }^{129}$ vitronectin and the basementmembrane-related proteins (e.g. heparan sulphate, laminin, ${ }^{128}$ nidogen/entactin, chondroitin sulphate and fibronectin ${ }^{125-127}$ ). The technology currently employed is not yet totally reliable and the immunohistochemical approach requires refinement to eliminate the discrepancies now apparent between reports. A fundamental problem in the interpretation of the immunohistochemistry is that many of the compounds identified within the exfoliation substance are normal basement membrane constituents which could have diffused in from the aqueous.
A major step forward in our appreciation of the complexity of the exfoliation syndrome is the fact that this is a systemic disease. Exfoliation substance can be identified in the conjunctiva and the orbital tissues (blood vessels, extraocular muscle, optic nerve sheaths and connective tissue septa). More recently exfoliation substance has been identified in skin, lungs, heart, liver, kidney and the cerebral meninges. ${ }^{124,126,127}$ These findings help to resolve the controversy of the origin of exfoliation substance within the eye, since the material appears to be an extracellular matrix product secreted by many types of connective tissue cell. Another fruitful technique applied to the constituents of exfoliation substance has been to identify carbohydrate epitopes. For example an epitope 'HNK1' is present on subsets of glycolipids and glycoproteins which are implicated in cell adhesion. These epitopes label strongly in exfoliation material and they may serve as a binding agent in the assembly of the complex molecules which make up exfoliation substance. ${ }^{130}$

\section{Silicone Oil Glaucoma}

Much of the published work on the effects of silicone oil on the ocular tissues has concentrated on the dispersion of emulsified oil within the vitreous and its presence in macrophages in preretinal membranes. ${ }^{131}$ The complication of secondary open angle glaucoma is now recognised ${ }^{132}$ but descriptions are sparse and confined to posterior segment pathology in human eyes ${ }^{133}$ and in animal eyes. ${ }^{134}$ Various authors have speculated that there is mechanical blockage either by the oil or by macrophages containing oil, with the added possibility that there may be damage to endothelial cells and secondary swelling of the trabecular beams. In the two cases on file, the predominant effect was occlusion of the intertrabecular spaces by macrophages containing spaces once occupied by oil droplets of varying size. Very few trabecular endothelial cells contained oil droplets, although occasional cells were found with small inclusions (Fig. 17).

\section{PRIMARY OPEN ANGLE GLAUCOMA}

The pathogenesis of primary open angle glaucoma remains unknown and both the clinical and pathological literature is filled with speculation and uncertainties. ${ }^{4,5,6,48}$ This is without doubt a reflection of the subtle and complex nature of a multifactorial disease. In addition many pathological reports have utilised trabeculectomy specimens, which in general are not suitable for the study of uveal and corneoscleral trabecular endothelial morphology since the cells are so easily damaged by the surgical manipulations. Another fundamental problem with the study of trabeculectomy specimens is that the sampling is 
limited in a disease which is patchy in the trabecular meshwork.

\section{Abnormal Extracellular Matrix in the Cribriform Layer}

The well-founded assumption that resistance to aqueous outflow in the normal outflow system lies in the cribriform layer (see above), was transferred to the outflow system in primary open angle glaucoma. Before any valid observations could be made all the investigators in this field were aware of the importance of documenting the changes which occur with ageing in the normal eye, ${ }^{8,14,45-47,135-138}$ and a large volume of information is now available, with different research groups placing emphasis on slightly different features of the cellular and extracellular constituents in the normal and disease states. I am in no position to enter into the debate on the pathogenesis of primary open angle glaucoma with regard to the importance of the obstruction by abnormal extracellular matrix in the cribriform layer: this has been extensively investigated by others. ${ }^{26,45,46,115,137,139,140}$

The fundamental problem with which morphologists have struggled is that of differentiating between the changes seen as part of the normal ageing process and those observed in primary open angle glaucoma. Interest has centred on 'plaque' material ${ }^{26,37,45-47,54}$ and on the fine fibrillar material located beneath the lining endothelium of Schlemm's canal (this material was recently shown to contain elastin) ${ }^{139}$, but the evidence obtained so far has been inconclusive in pinpointing a specific abnormality in primary open angle glaucoma. It is salutary to note that the most comprehensive study of the constituents of the extracellular matrix has been unable to make a clear distinction between the diseased tissue and the control. ${ }^{140}$

\section{Decline in Cell Population}

It is tempting to speculate that the constant demand on the trabecular endothelial cells to behave as phagocytes leads to a gradual depletion in the cell population - a morphological feature which is now well-documented. ${ }^{141-143}$ A good case has been made to show that cell depletion makes a significant contribution in primary open angle glaucoma, the hypothesis being that the disease is an exaggeration of the normal ageing process, but the evidence is not totally convincing. Certainly the abnormality does not appear to lie in the capacity of the lining endothelium of Schlemm's canal to produce invagination-vacuoles. A study was made of the lining endothelium of the canal by scanning electron microscopy to estimate the numbers of pores (i.e. representations of flow channels) in normal eyes obtained at autopsy and eyes similarly obtained from patients suffering from primary open angle glaucoma. ${ }^{144}$ The anterior chambers were perfused at a pressure of $15 \mathrm{mmHg}$ and the numbers and sizes of the pores in the lining endothelium were measured. Careful morphometric analysis failed to detect any significant difference between the normal and the diseased tissue. ${ }^{144}$

One of the intriguing features of primary open angle glaucoma is that in spite of the high intraocular pressure, Schlemm's canal is found to be open in the majority of well preserved specimens. ${ }^{140}$ If the previously described studies on the effects of partial angle closure are taken into account, it would be reasonable to assume that prolonged pressure would break down attachments in the cribriform layer and that this would proceed to inner/outer wall apposition in the canal. That this does not occur may be attributed to the rigidity of the extracellular matrix in the cribriform layer, but this assumption was not confirmed by the distension of the cribriform layer which occurred in elderly eyes subject to highpressure fixation. ${ }^{34}$

It would therefore seem reasonable to propose that narrowing of the collector channels would in some cases increase resistance to such a level that distension of the cribriform layer would be prevented by a raised pressure in Schlemm's canal. According to Poiseuille's law, a reduction in channel diameter to $80 \%$ of the original makes it necessary to double the pressure to maintain the same flow rate. In a light microscopic study of 100 trabeculectomy specimens, selected on the basis of good-quality morphology, I found that the canal was open in $94 \%$ and that fibrous replacement of the trabeculae with enlargement of the scleral spur and narrowing of the canal occurred in $50 \%$. When collector channels were identified $60 \%$ were found to be narrowed by deposition of fibrous tissue beneath the endothelium: a feature which was emphasised by Ashton ${ }^{3}$ some 35 years ago.

These non-specific and rather inconspicuous abnormalities lead me to suggest that the holistic approach should be taken to the pathology of the trabecular meshwork in primary open angle glaucoma - the relatively minor changes which occur throughout the outflow system in the disease state are probably too subtle for detection by morphological investigation. We must now rely on the molecular biologists, who can investigate the biochemical characteristics and synthetic capabilities ${ }^{8}$ of the normal and abnormal trabecular endothelial cells at a level undreamed of 35 years ago. In 1960 Ashton ${ }^{3}$ ended his Doyne lecture with the following words:

Today there can be no brilliant conquests to lay in tribute to our founder for as I have tried to show, research in this field is still developing, and as 
orthodox concepts dissolve under the impact of new discoveries so further possibilities unfold. We are on shifting ground and this has been a progress report, but no doubt this topic will again be chosen by a Doyne Lecturer. To him across the years I bequeath these words, probably to smile at - just possibly to build upon - but we must leave him entirely to write the conclusions.

I can only end by saying that I echo these words.

It is a great pleasure to record the names of the research workers and the technicians who have collaborated over the past decades in the study of the normal and the diseased outflow system. These include Professor Ian Grierson, Dr Paul G. McMenamin, Dr George E. Marshall, Dr Anastassos G. Konstas and Dr John Ainsworth. Dr Ali Amanat of Great Yarmouth deserves special recognition for providing untraumatised trabeculectomy specimens over the last decade. In addition I am most grateful to Mrs Dorothy Aitken and Mr James A. W. Ralston for their highly skilled technical assistance. Mrs Sophia Cameron has provided invaluable collaboration for the recent studies of trabeculitis and closed angle glaucoma. Miss Sandra Howat is to be thanked for expert secretarial assistance.

Without the environment and the stimulation provided by Professor Wallace Foulds the research would not have been possible.

This work has been supported by the Medical Research Council, the Wellcome Trust, the Scottish Home and Health Department, the Guide Dogs for the Blind Association and the Ross Foundation for the Prevention of Blindness.

Keywords: Glaucoma, Morphology, Trabecular meshwork.

\section{REFERENCES}

1. Catford GV. Our founder, Robert Doyne: a short biographical tribute. Trans Ophthalmol Soc UK 1976; 96:285-9.

2. Doyne RW. Notes on the more common diseases in the eye. London: HK Lewis, 1896:1-41.

3. Ashton N. The exit pathways of the aqueous. Trans Ophthalmol Soc UK 1968;80:397-419.

4. Cairns JE. Glaucoma. London: Harcourt Brace, 1986.

5. Rich R, Shields MM, Krupin T (eds). The glaucomas. Vols 1 and 2. St Louis: CV Mosby, 1989.

6. Shields BM. Textbook of glaucoma. 3rd ed. Baltimore: Williams and Wilkins, 1992.

7. Bill A, Maepea O. Mechanisms and routes of aqueous humour and drainage. In: Albert DM, Jakobiec FA, eds. Principles and practice of ophthalmology. Philadelphia: WB Saunders, 1994:206-26.

8. Polansky JR, Alvarado JA. Cellular mechanisms influencing the aqueous humour outflow facility. In: Albert DM, Jakobiec FA, eds. Principles and practice of ophthalmology. Philadelphia: WB Saunders, 1994: 226-51.

9. Coupland SE, Penfold P, Billson F, Hoffmann F. Immunohistochemistry of the glaucomatous and normal human trabecular meshwork. German J Ophthalmol 1994;3:168-74.

10. Tamm ER, Flugel C, Stefani FH, Lutjen-Drecoll E. Nerve endings with structural characteristics of mechanoreceptors in the human scleral spur. Invest Ophthalmol Vis Sci 1994;35:1157-66.

11. Garron L, Feeney ML, Hogan MJ, McEwan WK. Electron microscopic studies of the human eye. Am J Ophthalmol 1958;46:27-56.

12. Holmberg AS. The fine structure of the inner wall of Schlemm's canal. Arch Ophthalmol 1959;62:956-8.

13. Tripathi RC. Mechanisms of the aqueous outflow across the trabecular wall of Schlemm's canal. Exp Eye Res 1971;11:116-21.

14. Tripathi RC, Tripathi BJ. Functional anatomy of the chamber angle. In: Jakobiec FA, ed. Ocular anatomy, embryology and teratology. Philadelphia: Harper and Row, 1982:197-284.

15. Johnstone MA, Grant WM. Pressure dependent changes in structures of the aqueous outflow system of human and monkey eyes. Am J Ophthalmol 1973;75:365-83.

16. Grierson I, Johnson NF. The postmortem vacuoles $\mathrm{c}$ : Schlemm's canal. In: Lee WR, ed. Current research in ophthalmic electron microscopy. Berlin: SpringerVerlag, 1981:41-56.

17. Lee WR, Grierson I. Relationships between intraocular pressure and the morphology of the outflow apparatus. Trans Ophthalmol Soc UK 1974;94:430-49.

18. Grierson I, Lee WR. Pressure-induced changes in the ultrastructure of the endothelium lining Schlemm's canal. Am J Ophthalmol 1975;80:863-84.

19. Grierson I, Lee WR. Light microscopic quantitation of the endothelial vacuoles in Schlemm's canal. Am J Ophthalmol 1977;84:234-46.

20. Lee WR, Grierson I. Pressure effects on the endothelium of the trabecular wall of Schlemm's canal: a study by scanning electron microscopy. Graefes Arch Klin Exp Ophthalmol 1975;196:255-65.

21. Grierson I, Lee WR. The fine structure of the trabecular meshwork at graded levels of intraocular pressure. I. Pressure effects within the near physiological range (8-30 mmHg). Exp Eye Res 1975;20: 505-21.

22. Grierson I, Lee WR. The fine structure of the trabecular meshwork at graded levels of intraocular pressure. II. Pressure outside the physiological range (0 and $55 \mathrm{mmHg}$ ). Exp Eye Res 1975;20:523-30.

23. Grierson I, Lee WR, Abraham S. The pathways for the drainage of aqueous humour into Schlemm's canal. Trans Ophthalmol Soc UK 1977;7:719-25.

24. Alvarado J, Murphy C, Juster R. Trabecular meshwork cellularity in primary open angle glaucoma and nonglaucomatous normals. Ophthalmology 1984;91: 564-79.

25. Bill A. Some aspects of aqueous humour drainage. Eye 1993;7:14-9.

26. Rohen JW, Lutjen-Drecoll E. Morphology of aqueous outflow pathways in normal and glaucomatous eyes. In: Rich R, Shields MB, Krupin T, eds. The glaucomas. St Louis: Mosby, 1989:41-7.

27. McMenamin PG, Lee WR. Effects of prolonged intracameral perfusion with mock aqueous humour on the morphology of the primate outflow apparatus. Exp Eye Res 1986;43:129-41.

28. McMenamin PG. Functional and morphological studies of the primate outflow apparatus. PhD Thesis, University of Glasgow, 1981.

29. Sawaguchi S, Yue B, Yeh P, Tso MOM. Effects of intracameral injection of chondroitinase $\mathrm{ABC}$ in vivo. Arch Ophthalmol 1992;110:110-7.

30. Grierson I, Lee WR, Abraham S. Effects of 
pilocarpine on the human outflow apparatus. $\mathrm{Br} \mathrm{J}$ Ophthalmol 1978;62:302-13.

31. Lee WR, Grierson I, Abraham S. Comparative anatomy of the angular tissues in the baboon and human eye in relation to the pilocarpine response. Trans Ophthalmol Soc UK 1977;97:726-31.

32. Grierson I, Lee WR, Abraham S. The effects of topical pilocarpine on the morphology of the outflow apparatus of the baboon. Invest Ophthalmol 1979;18:346-55.

33. McMenamin PG, Lee WR, Grierson I, Grindle J. Giant vacuoles in the lining endothelium of Schlemm's canal in the human eye after topical timolol maleate. Invest Ophthalmol Vis Sci 1983;24:339-42.

34. Ainsworth JR, Lee WR. Effects of age and high pressure fixatior on the lining endothelium of Schlemm's caic... Invest Ophthalmol $V$ is Sci 1990;31:745-50.

35. Lee WR. The study of the passage of particles through the endothelium of the outflow apparatus of the monkey eye by scanning and transmission electron microscopy. Trans Ophthalmol Soc UK 1971;91: 687-705.

36. Rohen JW, van der Zypen E. The phagocytic activity of the trabecular meshwork endothelium: an electron microscopic study of the vervet (Cercopitheus aethiops). Graefes Arch Klin Exp Ophthalmol 1968;175:143-60.

37. Rohen JW, Lutjen-Drecoll E. Biology of the trabecular meshwork. In: Lutjen-Drecoll E, ed. Basic aspects of glaucoma research. Stuttgart: Schattauer, 1981:141-66.

38. Grierson I, Day J, Unger WG, Ahmed A. Phagocytosis of latex microspheres by bovine meshwork cells in culture. Graefes Arch Clin Exp Ophthalmol 1986; 224:536-44.

39. Shirato S, Murphy CG, Bloom E; Franse-Carmen L, Maglio MT, Polansky JR, Alvarado JR. Kinetics of phagocytosis in trabecular meshwork cells: flow cytometry and morphometry. Invest Ophthalmol Vis Sci 1989;30:2499-511.

40. Park CH, Latina MA. Effects of gamma interferon on human trabecular meshwork cell phagocytosis. Invest Ophthalmol Vis Sci 1993;34:2228-36.

41. Epstein DL, Freddo TF, Anderson PJ, Patterson MM, Bassett-Chu S. Experimental obstruction to aqueous outflow by pigment particles in living monkeys. Inv Ophthalmol Vis Sci 1986;27:387-95.

42. Maeepa O, Bill A. Pressures in the juxtacanalicular tissue and Schlemm's canal in monkeys. Exp Eye Res 1992;54:879-83.

43. Ethier C, Kamm R, Palazewski B. Calculations of flow resistance in the juxtacanalicular meshwork. Invest Ophthalmol Vis Sci 1986;127:1741-50.

44. Seiler T, Wollansek J. The resistance of the trabecular meshwork to aqueous humour outflow. Graefes Arch Clin Exp Ophthalmol 1985;223:88-91.

45. Grierson I. What is open angle glaucoma? Eye 1987;1:15-28.

46. Rohen JW, Futa R, Lutjen-Drecoll E. The fine structure of the cribriform meshwork in normal and glaucomatous eyes as seen in tangential sections. Invest Ophthalmol Vis Sci 1981;21:574-85.

47. Lutjen-Drecoll E, Shimuzu R, Rohrbach M, Rohen JW. Quantitative analysis of plaque material in the inner and outer wall of Schlemm's canal in normal and glaucomatous eyes. Exp Eye Res 1986;42:443-5.
48. Shiose Y. Intraocular pressure: new perspectives. Surv Ophthalmol 1990;34:413-5.

49. Marshall GE, Konstas AG, Lee WR. Immunogold ultrastructural localisation of collagens in the aged human outflow system. Ophthalmology 1991;98: 692-700.

50. Marshall GE, Konstas AG, Lee WR. Immunogold localisation of type IV collagen and laminin in the aging outflow system. Exp Eye Res 1990;51:691-9.

51. Marshall GE, Konstas AG, Lee WR. Collagens in ocular tissues. Br J Ophthalmol 1993;77:515-24.

52. Montes GS, Bezerra MSF, Junquiera LCU. Collagen distribution in tissues. In: Ruggieri A, Motta PM, eds. Ultrastructure of the connective tissue matrix. Boston: Martinus Nijhoff, 1984:65-88.

53. Tripathi BJ, Hansen M, Li J, Tripathi RC. Identification of type VI collagen in the trabecular meshwork and expression of its mRNA by trabecular cells. Exp Eye Res 1994;58:181-8.

54. Lutjen-Drecoll E, Rittig M, Rauterberg EA, Jander $\mathrm{R}$, Mollenhauer J. Immunomicroscopical study of type VI collagen in the trabecular meshwork of normal and glaucomatous eyes. Exp Eye Res 1989;48:139-147.

55. Grierson I, Lee WR. Acid mucopolysaccharides in the outflow apparatus. Exp Eye Res 1975;21:417-31.

56. Tawara A, Varner HH, Holleyfield JG. Distribution and characterisation of sulfated proteoglycans in the human trabecular tissue. Invest Ophthalmol Vis Sci 1989;20:2215-31.

57. Chapman SA, Bonshek RE, Stoddart RW, Mackenzie KR, McLeod D. Localisation of alpha $(2,3)$ and alpha $(2,6)$ linked terminal sialic acid groups in human trabecular meshwork. $\mathrm{Br}$ J Ophthalmol 1994; 78:632-7.

58. Gong H, Freddo TF, Johnson M. Age-related changes of sulfated proteoglycans in the normal human trabecular meshwork. Exp Eye Res 1992;55:691-709.

59. Fourman S. Diagnosing acute angle closure glaucoma: a flow chart. Surv Ophthalmol 1989;33:491-4.

60. Krupin T, Feitl ME. Glaucoma associated with uveitis. In: Rich R, Shields MM, Krupin T, eds. The glaucomas. St Louis: CV Mosby, 1989: 1205-23.

61. Cantor LB, Schlaegel TF, Abrams JH, Weber JC. Intraocular pressure in anterior uveitis. Glaucoma 1992;14:155-8.

62. Falcon MG, Williams HP. Herpes simplex keratouveitis and glaucoma. Trans Ophthalmol Soc UK 1978;98:101-4.

63. Hogan MJ, Kimura SJ, Thygeson P. Pathology of herpes simplex keratoiritis. Am J Ophthalmol 1964;57:551-64.

64. Spencer WH. Pathological physiology of the secondary glaucomas. In: Cairns JE, ed. Glaucoma. Vol. 1. London: Harcourt Brace, 1986:chap 20.

65. Wilhelmus K, Grierson T, Watson PG. Histopathologic and clinical associations of scleritis and glaucoma. Am J Ophthalmol 1981;91:697-705.

66. Panek WC, Holland GN, Lee DA, Christensen RE Glaucoma in patients with uveitis. $\mathrm{Br} \mathrm{J}$ Ophthalmol 1990;74:223-7.

67. Epstein DL, Hashimoto JM, Grant WM. Serum obstruction of aqueous outflow in enucleated eyes. Am J Ophthalmol 1978;86:101-6.

68. Kass MA, Podos SM, Moses RA, Becker B. Prostaglandin $E_{1}$ and aqueous humour dynamics. Invest Ophthalmol Vis Sci 1972;11:1022-7.

69. Howes EL Jr, Cruse VK. The structural basis of altered vascular permeability following intraocular inflammation. Arch Ophthalmol 1978;96:1668-76. 
70. Roth M, Simmons RJ. Glaucoma associated with precipitates on the trabecular meshwork. Ophthalmology 1979;86:1613-8.

71. Schlaegel TF. Complications of uveitis. Int Ophthalmol Clin 1977;17:65-74.

72. Foets B, van den Oord J, Engelmann K, Missotten LA. Comparative immunohistochemical study of human corneotrabecular tissue. Graefes Arch Clin Exp Ophthalmol 1992;230:269-74.

73. Lynch MG, Peeler JS, Brown RH, Niederkorn JY. Expression of HLA class I and II antigens on cells of the human trabecular meshwork. Ophthalmology 1987;94:851-7.

74. Tripathi BJ, Tripathi RC, Wong P, Raja S. Expression of HLA by the human trabecular meshwork and corneal endothelium. Exp Eye Res 1992;51:269-76.

75. Forrester JV, McMenamin PG, Holthouse I, Lumsden $\mathrm{L}$, Liversidge J. Localisation and characterisation of major histocompatibility complex class II-positive cell in the posterior segment of the eye: implications for induction of auto-immune uveoretinitis. Invest Ophthalmol Vis Sci 1994;35:64-77.

76. McMenamin PG, Crewe J, Morrison S, Holt PG. Immunomorphic studies of macrophages and MHC class II-positive dendritic cells in the iris and ciliary body of the rat, mouse and human eye. Invest Ophthalmol Vis Sci 1994;35:3234-50.

77. Missotten L. Immunology and herpetic keratitis. Eye 1994;8:12-21.

78. O'Connor GR. Heterochromic iridocyclitis. Trans Ophthalmol Soc UK 1985;104:219-31.

79. Jones NP. Fuchs' heterochromic uveitis: an update. Surv Ophthalmol 1993;37:253-72.

80. La Hay E, de Jong PTVM, Kijlstra A. Fuchs' heterochromic cyclitis: review of the literature on the pathogenetic mechanisms. $\mathrm{Br} \mathrm{J}$ Ophthalmol 1994;78: 307-12.

81. Goldberg MF, Erozan YS, Duke JR, Frost JK. Cytopathologic and histopathologic aspects of Fuchs' heterochromic iridocyclitis. Arch Opthalmol 1965;74: 604-9.

82. Perry HD, Yanoff M, Scheie HG. Rubeosis in Fuchs' heterochromic iridocyclitis. Arch Ophthalmol 1975; 93:337-9.

83. Rohen HJW, Linner E, Witmer R. Electron microscopic studies on the trabecular meshwork in two cases of corticosteroid glaucoma. Exp Eye Res 1973; 17:19-31.

84. Grierson I, Lee WR, McMenamin PG. The morphological basis of drug action on the outflow system of the eye. Res Clin Forums 1981;3:7-25.

85. Wilson K, McCartney MD, Miggans ST, Clark AF. Dexamethasone induced ultrastructural changes in cultured human trabecular meshwork cells. Curr Eye Res 1993;12:783-94.

86. Steely HT, Browder SL, Julian MB, Miggans ST, Wilson KL, Clark AF. The effects of dexamethasone on fibronectin expression in cultured human trabecular meshwork cells. Invest Ophthalmol Vis Sci 1992;33:42-50.

87. Partridge CA, Weistein BI, Southren AL, Gerritsen ME. Dexamethasone induces specific proteins in human trabecular meshwork cells. Invest Ophthalmol Vis Sci 1989;30:1843-7.

88. Yun AJ, Murphy CG, Polansky JR, Newsome DA, Alvarado JA. Proteins secreted by human trabecular cells. Invest Ophthalmol Vis Sci 1989;30:2021-2.

89. Tripathi BJ, Millard CB, Tripathi RC. Corticosteroids induce a sialated glycoprotein (Cort-GP) in trabecular cells in vitro. Exp Eye Res 1990;51:735-7.

90. Johnson DH, Bradley JMB, Acott TS. The effect of dexamethasone on glycosaminoglycans of human trabecular meshwork in perfusion organ culture. Invest Ophthalmol Vis Sci 1990;31:2568-71.

91. Rosenbaum JT, Samples JR, Seymour B, Langlois L, David L. Chemotactic activity of lens proteins and the pathogenesis of phacolytic glaucoma. Arch Ophthalmol 1987;105:1582-4.

92. Flocks M, Littwin CS, Zimmerman LE. Phacolytic glaucoma: a clinicopathologic study of one hundred and thirty-eight cases of glaucoma associated with hypermature cataract. Arch Ophthalmol 1955:54:37-45.

93. Bron AJ, Habgood JO. Morgagnian cataract. Trans Ophthalmol Soc UK 1976;96:265-77.

94. Vrensen G, Kappelhof J, Willekens B. Morphology of the aging human lens. Lens Eye Toxicity Res 1990;7:1-30.

95. Costello MJ, Oliver TN, Cobo LM. Cellular architecture in age related human nuclear cataracts. Invest Ophthalmol Vis Sci 1992;33:3209-27.

96. Vrenson G, van Marle JV, van Been $H$, Willekens B. Membrane architecture as a function of lens fibre maturation: a freeze fracture and scanning electron microscopic study in the human lens. Exp Eye Res 1992;54:433-46.

97. Brooks AMV, Grant G, Gillies WE. Comparison of specular microscopy and examination of aspirate in phacolytic glaucoma. Ophthalmology 1990;97;85-9.

98. Epstein DL, Jedziniak JA, Grant WM. Identification of heavy molecular weight soluble protein in aqueous humor in human phacolytic glaucoma. Invest Ophthalmol Vis Sci 1978;17:398-402.

99. Richter C, Epstein DL. Lens-induced open angle glaucoma. In: Ritch R, Shields MB, Krupin T, eds. The glaucomas. St Louis: CV Mosby, 1989:1017-26.

100. McMenamin PG, Lee WR. Ultrastructural pathology of melanomalytic glaucoma. Br J Ophthalmol 1986; 70:895-906.

101. El Baba F, Hagler WS, DeLa Cruz A, Green WR. Choroidal melanoma with pigment dispersion in vitreous and melanomalytic glaucoma. Ophthalmology 1988;95:370-7.

102. Inomata H, Bill A, Smelser GK. Aqueous humor pathways through the trabecular meshwork and into Schlemm's canal in the cynomolgus monkey (Macacus. irus): an electron microscopic study. Am J Opthalmol 1972;73:760-89.

103. Fenton RH, Zimmerman LE. Hemolytic glaucoma, an unusual cause of acute open angle secondary glaucoma. Arch Ophthalmol 1963;70:236-9.

104. Grierson I, Lee WR. Erythrocyte phagocytosis in the human trabecular meshwork. Br J Ophthalmol 1973; $57: 400-15$.

105. Grierson I, Lee WR, Abraham SA. Further observations on the process of haemophagocytosis in the human outflow system. Graefes Arch Klin Exp Ophthalmol 1978;208:49-64.

106. Campbell DG. Ghost cell glaucoma. In: Ritch R, Shields MB, eds. The secondary glaucomas. St Louis: CV Mosby, 1982:320-7.

107. Shields CL, Shields JA, Shields MB, Augsburger JJ. Prevalence and mechanisms of secondary intraocular pressure elevation in eyes with intraocular tumours. Ophthalmology 1987;94:839-46.

108. Bechrakis N, Lee WR. Dedifferentiation potential of iris melanomas. Fortschtr Ophthalmol 1991;88:651-6. 
109. Farrar SM, Shields BM. Current concepts in pigmentary glaucoma. Surv Ophthalmol 1993;37:233-52.

110. Richardson TM. Pigmentary glaucoma. In: Ritch R, Shields MB, Krupin T, eds. The glaucomas. St Louis: CV Mosby, 1989:981-95.

111. Murphy CG, Johnson M, Alvarado JA. Juxtacanalicular tissue in pigmentary and primary open angle glaucoma: the hydrodynamic role of pigment and other constituents. Arch Ophthalmol 1992;110:79-85.

112. Fine BJ, Yanoff M, Scheie HG. Pigmentary glaucoma: a histologic study. Trans Am Acad Ophthalmol Otolaryngol 1975;78:314-25.

113. Richardson TM, Hutchinson BT, Grant WM. The outflow tract in pigmentary glaucoma: a light and electron microscopic study. Arch Ophthalmol 1977;195:1015-25.

114. Alvarado JA, Murphy CG. Outflow obstruction in pigmentary and primary open angle glaucoma. Arch Ophthalmol 1992;110:1769-78.

115. Rodrigues MM, Spaeth GL, Sivalingam E, Weinreb S. Histopathology of 150 trabeculectomy specimens in glaucoma. Trans Ophthalmol Soc UK 1976;96:245-55.

116. Iwamoto $\mathrm{T}$, Witmer R, Landolt $\mathrm{E}$. Light and electron microscopy in absolute glaucoma with pigment dispersion phenomena and contusion angle deformity. Am J Ophthalmol 1971;72:420-34.

117. Konstas AG, Jay JL, Marshall GE, Lee WR. Prevalence, diagnostic features and response to trabeculectomy in exfoliation glaucoma. Ophthalmology 1993;100:619-27.

118. Streeten BAW, Dark AJ. Pseudoexfoliation syndrome. In: Garner A, Klintworth GK, eds. Pathobiology of ocular disease. New York: Marcel Dekker, 1994:591-630.

119. Brinchmann-Hansen O, Albreksten T, Anmarkrud N. Pilocarpine drops do not reduce intraocular pressure sufficiently in pseudoexfoliation glaucoma. Eye 1993;7:511-6.

120. Ringvold A. Electron microscopy of the trabecular meshwork in eyes with exfoliation syndrome (pseudoexfoliation of the lens capsule). Virch Arch (Pathol Anat) 1971;353:110-27.

121. Konstas AG, Marshall GE, Cameron SA, Lee WR. Morphology of iris vasculopathy in exfoliation glaucoma. Acta Ophthalmol (Copenh) 1993;71:751-9.

122. Helbig H, Schloetzer-Schrehardt U, Noske W, Kellner $\mathrm{U}$, Foerster $\mathrm{MH}$. Anterior chamber hypoxia and iris vasculopathy in pseudoexfoliation syndrome. German J Ophthalmol 1994;3:148-53.

123. Li Z-Y, Streeten BW, Wallace RN. Association of elastin with pseudoexfoliative material: an immunoelectron microscopic study. Curr Eye Res 1988; 7:1163-72.

124. Streeten BW, Li ZY, Wallace RN, Eagle RC, Keshgegian AA. Pseudoexfoliative fibrillopathy in visceral organs of a patient with pseudoexfoliation syndrome. Arch Ophthalmol 1992;110:1757-62.

125. Schloetzer-Schrehardt U, Doerfler S, Naumann GOH. Immunohistochemical localisation of basement membrane components in pseudoexfoliation material of the lens capsule. Curr Eye Res 1992;11:343-55.

126. Schloetzer-Schrehardt UM, Koca MR, Naumann $\mathrm{GOH}$, Volkholz H. Pseudoexfoliation syndrome: ocular manifestations of a systemic disorder. Arch Ophthalmol 1992;110:1752-6.

127. Schloetzer-Schrehardt U, Kuchle M, Dorfler S, Naumann GOH. Pseudoexfoliative material in the eyelid skin of pseudoexfoliation-suspect patients: a clinico-histological correlation. German J Ophthalmol 1993;2:51-60.

128. Konstas AG, Marshall GE, Lee WR. Immunogold localisation of laminin in the normal and exfoliation iris. Br J Ophthalmol 1990;74:450-7.

129. Vogiatzis A, Marshall GE, Konstas AGP, Lee WR. Immunogold study of non-collagenous matrix components in normal and exfoliative iris. $\mathrm{Br} \mathrm{J}$ Ophthalmol 1994;78: 850-8.

130. Uusitalo M, Kivela T, Tarkkanen A. Immunoreactivity of exfoliation material for the cell adhesion related HNK1-carbohydrate epitope. Arch Ophthalmol 1993;111:1419-23.

131. Ni C, Wang WJ, Albert DM, Schepens CL. Intravitreous silicone injection: histologic findings in a human eye after 12 years. Arch Ophthalmol 1983;101: 1399-401.

132. Nguyen QH, Lloyd MA, Heuer DK, Baerveldt G, Minckler DS, Lean JS, Liggett PE. Incidence and management of glaucoma after intravitreal silicone oil injection for complicated retinal detachments. Ophthalmology 1992;99:1520-6.

133. Kirchof B, Tavakolian H, Paulmann H, Heimann K. Histopathological findings in eyes after silicone oil injection. Graefes Arch Clin Exp Ophthalmol 1986;224:34-7.

134. Suzuki M, Ukada I, Takeuchi S, Ishii Y, Yamashita H, Hori S. Effect of silicone oil on ocular tissues. Jpn J Ophthalmol 1991;35:282-91.

135. McMenamin PG, Lee WR. Age-related changes in extracellular materials in the inner wall of Schlemm's canal. Graefes Arch Klin Exp Ophthalmol 1980; 212:159-72.

136. McMenamin PG, Lee WR, Aitken DN. Age-related changes in the human outflow apparatus. Ophthalmology 1986;93:194-209.

137. Lutjen-Drecoll E, Futa R, Rohen JW. Ultrahistochemical studies on tangential sections of the trabecular meshwork in normal and glaucomatous eyes. Invest Ophthalmol Vis Sci 1981;21:563-73.

138. Oates DC, Belcher CD. Aging changes in trabecular meshwork, iris and ciliary body. In: Albert DM, Jakobiec FA, eds. Principles and practice of ophthalmology: basic sciences. Philadelphia: WB Saunders, 1994:697-701.

139. Umihara J, Nagata S, Nohara M, Hanai T, Usuda N, Segawa K. Localisation of elastin in the normal and glaucomatous human trabecular meshwork. Invest Ophthalmol Vis Sci 1994;35:486-94.

140. Rohen JW, Lutjen-Drecoll E, Flugel C, Meyer M, Grierson I. Ultrastructure of the trabecular meshwork in untreated cases of primary open angle glaucoma. Exp Eye Res 1993;56:683-92.

141. Alvarado J, Murphy C, Polansky J. Age-related changes in trabecular meshwork cellularity. Invest Ophthalmol Vis Sci 1981;21:714-27.

142. Alvarado J, Murphy C, Juster R. Trabecular meshwork cellularity in primary open angle glaucoma and non-glaucomatous controls. Ophthalmology 1984;91: 564-79.

143. Grierson I, Howes R. Age related depletion of the cell population in the human trabecular meshwork. Eye 1987;1:204-10.

144. Allingham RR, De Kater AW, Ethier CR, Anderson PJ, Hertzmark E, Epstein DL. The relationship between pore density and outflow facility in human eyes. Invest Ophthalmol Vis Sci 1992;33:1661-9. 